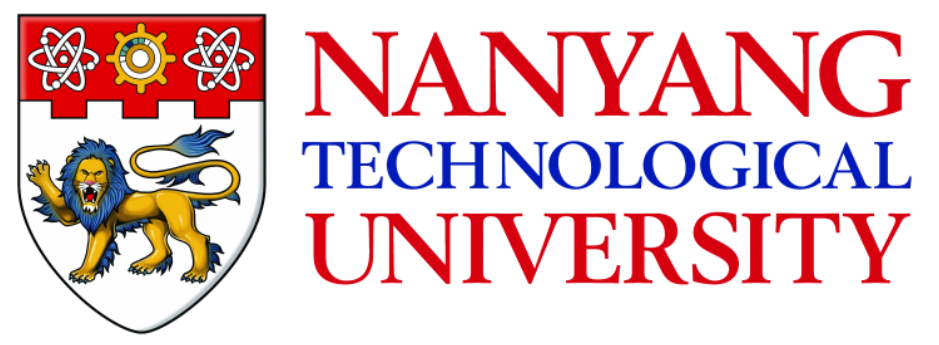

\title{
DEVELOPMENT OF HOLLOW FIBER MEMBRANES FOR SOLVENT RESISTANT NANOFILTRATION
}

\section{LIM SIOW KEE}

School of Civil and Environmental Engineering 2017 


\section{DEVELOPMENT OF HOLLOW FIBER MEMBRANES FOR SOLVENT RESISTANT NANOFILTRATION}

\section{LIM SIOW KEE}

School of Civil and Environmental Engineering

A thesis submitted to the Nanyang Technological University in partial fulfillment of the requirement for the degree of Master of Engineering 


\section{ACKNOWLEDGEMENTS}

First of all, I would like to express my deepest gratitude to my supervisors, Prof. Wang Rong and Prof. Bae Tae-Hyun, for their continuous encouragement, support and guidance throughout my studies. Their understanding, patience and invaluable advice have greatly helped me get through the hard times when I faced challenges in my research and personal life. I would also like to thank my mentor, Prof. Anthony G. Fane, for his helpful comments regarding my research topic, Prof. Wang Jing-Yuan as my qualification examination reviewer, and Prof. William B. Krantz for his workshops and suggestions.

Next, I would like to express my heartfelt appreciation to the staff and students in SMTC and Prof Bae's group for their generous help, support and sharing of knowledge and experiences. They include Laurentia Setiawan, Victor Sim, Goh Kunli, Zhang Yuan, Zhang Lizhi, Shi Lei, Liu Chang, Fang Wangxi, Zhao Shanshan, Sunee Wongchitphimon, Loh Chun Heng, Li Xuesong, Liao Yuan, Tian Miao, Zhao Jie, Yao Lei, Wei Jing, Wang Yining, Lee Jian Yuan, Chen Yunfeng, Jin Mengyi, Gong Heqing, Zeng Zhiping, and many others who have helped me in one way or another.

I am also deeply grateful to the staff from IGS, NEWRI and CEE for their kind assistance in administrative matters, purchasing and equipment usage. They include Ellen Heng, Andrea Fong, Deirdre Lim, Hera Catharina Adam, Zan Ong, Chan Wai Yee, Joseph Kwan, Han Yuan, Xu Yanfang, Maria Chong, Pearlyn See and Ng Hui Leng.

Last but not least, I would like to acknowledge the Interdisciplinary Graduate School (IGS), Nanyang Technological University, for providing my scholarship, and Nanyang Environment and Water Research Institute (NEWRI) and Singapore Membrane Technology Centre (SMTC) for the funding support and excellent research facilities. 


\section{TABLE OF CONTENTS}

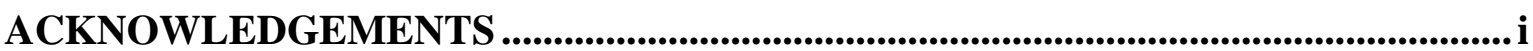

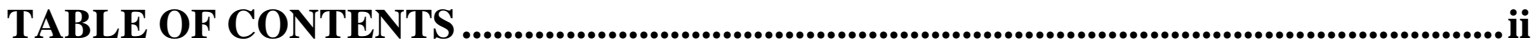

LIST OF PUBLICATIONS ........................................................................................ iv

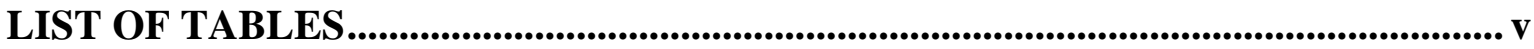

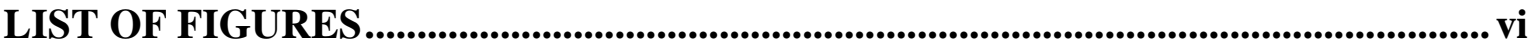

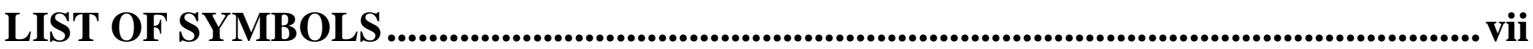

ABSTRACT ......................................................................................................................................... ix

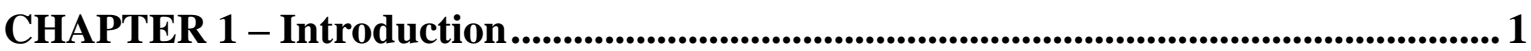

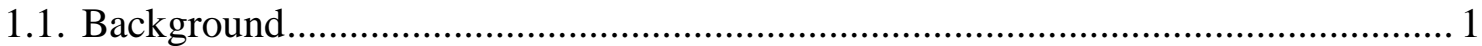

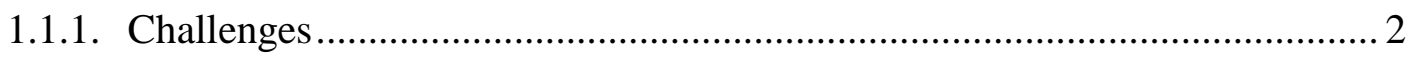

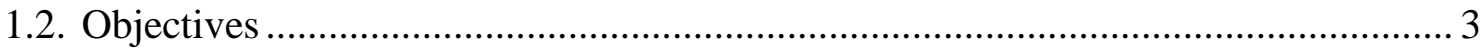

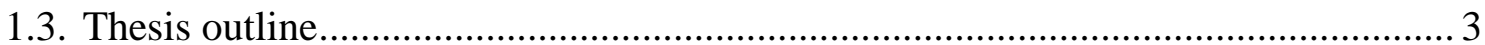

CHAPTER 2 - Literature Review .........................................................................5

2.1. Mass transfer in polymeric SRNF membranes ...................................................... 5

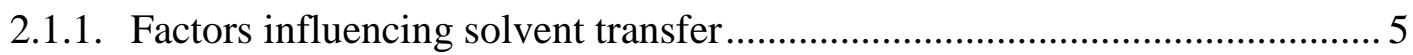

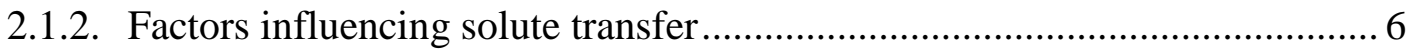

2.2. Development of polymer-based SRNF membranes .............................................. 6

2.2.1. Integrally skinned asymmetric membranes ............................................ 7

2.2.2. Thin film composite membranes ............................................................. 12

2.2.2.1. Interfacial polymerization ....................................................... 12

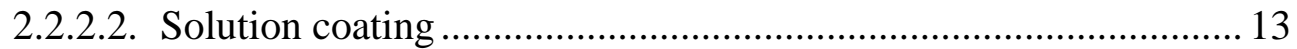

2.2.2.3. Layer-by-layer deposition of polyelectrolytes ............................ 15

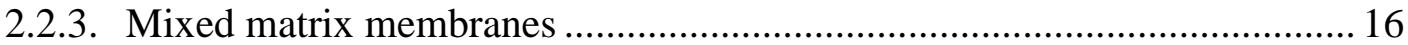

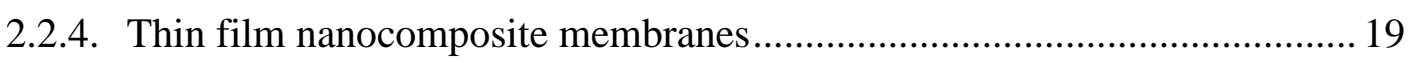

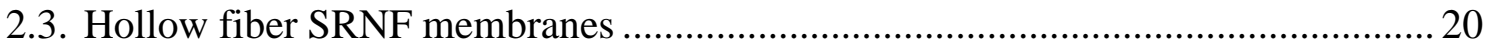

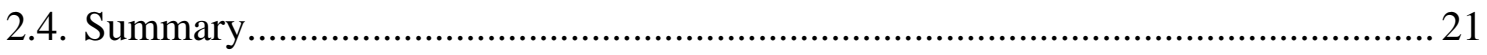


CHAPTER 3 - Polyamide-imide hollow fiber membranes crosslinked with amineappended inorganic networks for SRNF under low operating pressure.

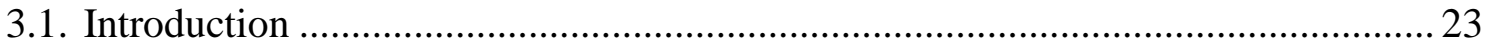

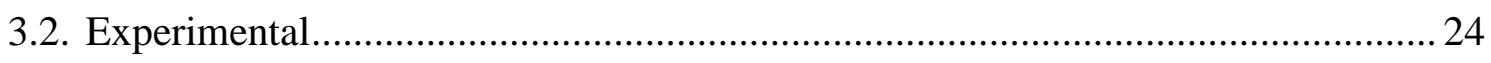

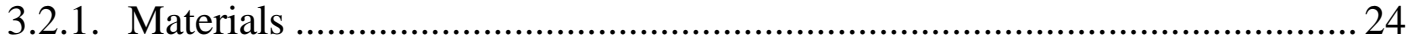

3.2.2. Fabrication of PAI hollow fiber substrates ............................................. 25

3.2.3. Post-treatment of PAI hollow fiber substrates ........................................... 25

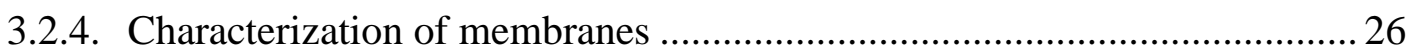

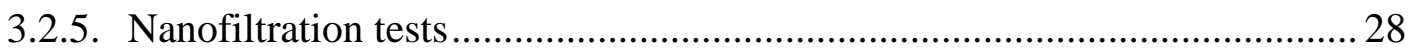

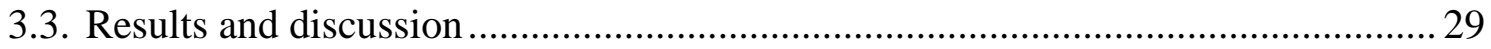

3.3.1. Characterization of PAI hollow fiber substrates ....................................... 29

3.3.2. Optimization of crosslinking conditions .................................................. 31

3.3.3. Characterization of crosslinked hollow fiber membranes ......................... 33

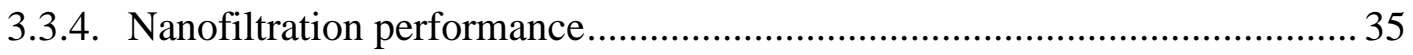

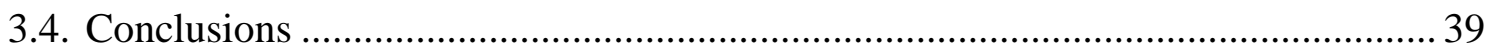

CHAPTER 4 - CONCLUSION \& RECOMMENDATIONS .......................................... 41

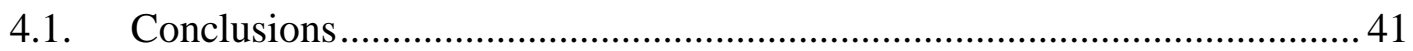

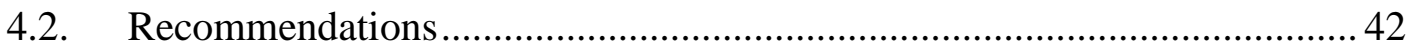

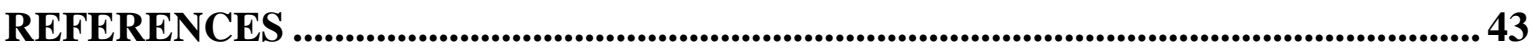




\section{LIST OF PUBLICATIONS}

1. S. K. Lim, K. Koh, T.-H. Bae, R. Wang, Polymer-Based Membranes for SolventResistant Nanofiltration: a Review, Chinese Journal of Chemical Engineering, under review with minor revision.

2. S. K. Lim, L. Setiawan, T.-H. Bae, R. Wang, Polyamide-imide hollow fiber membranes crosslinked with amine-appended inorganic networks for application in solvent-resistant nanofiltration under low operating pressure, Journal of Membrane Science, 501 (2016) 152-160. 


\section{LIST OF TABLES}

Table 1. Polymers used to prepare ISA SRNF membranes ........................................... 9

Table 2. Overview of the different types of commercial membranes for SRNF............... 22

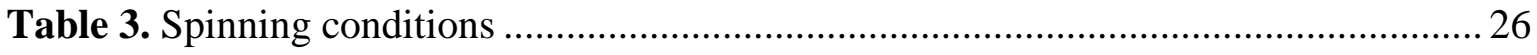

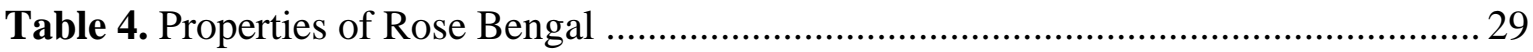

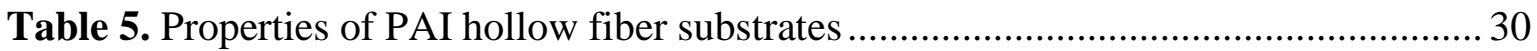

Table 6. Effect of crosslinking temperature on mechanical properties of membrane ........ 32

Table 7. Effect of crosslinking time on membrane properties......................................... 32

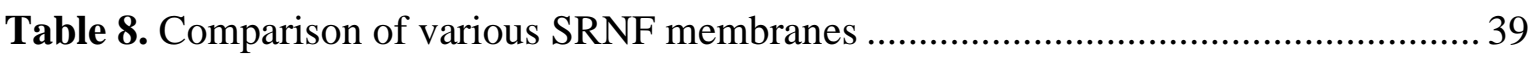




\section{LIST OF FIGURES}

Figure 1. Mechanism of crosslinking of Matrimid ${ }^{\circledR}$ with p-xylenediamine (Tin, Chung et al. 2003)

Figure 2. Schematic illustrations of the IP reaction to give (a) nanofilm of sub-10 nm in thickness using sacrificial cadmium hydroxide nanostrand layer (Karan, Jiang et al. 2015); (b) nanofilm using contorted monomers such as BHPF and TTSBI leading to microporosity and interconnectivity within the PA nanofilm (Jimenez-Solomon, Song et al. 2016) ........ 14 Figure 3. Crosslinking of P84 polyimide with APTMS (Siddique, Rundquist et al. 2014)18

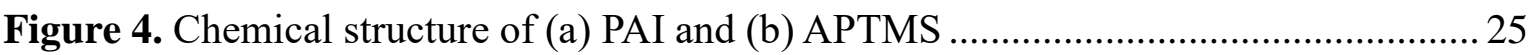

Figure 5. Typical set-up for hollow fiber spinning (Peng, Widjojo et al. 2012) ................ 26 Figure 6. SEM images of hollow fiber substrates: (a) and (b) cross-sections; (c) outer surfaces 30

Figure 7. Reaction mechanism between PAI and APTMS 31

Figure 8. FTIR spectra of \#1 membranes before and after crosslinking with $2 \%$ APTMS at $60{ }^{\circ} \mathrm{C}$ for 3 hours

Figure 9. Elemental map showing the distribution of Si on the cross-section of crosslinked membrane (\#1-H) 34

Figure 10. SEM images of \#2 membranes before and after the crosslinking: (a) Crosssection; (b) cross-section of outer skin area; (c) the surface of outer skin 35

Figure 11. IPA flux and RB rejection of membranes (operating conditions: 2 bar, room temperature)

Figure 12. DMF flux and RB rejection of membranes (operating conditions: 2 bar, room temperature); no flux was obtained for \#2-H 36

Figure 13. Pore size distribution of membranes 37

Figure 14. Long-term separation performance of \#1-H membrane in (a) IPA (b) DMF (feed solution: $35 \mu \mathrm{M}$ RB in IPA or DMF; operating conditions: 2 bar, room temperature) ...... 38 


\section{LIST OF SYMBOLS}

API Active pharmaceutical ingredient

APDEMS Aminopropyldiethoxymethylsilane

APTMS 3-aminopropyl trimethoxysilane

BHPF 9,9-bis(4-hydroxyphenyl)fluorene

CMS Carbon molecular sieve

CV Crystal violet

DCM Dichloromethane

DCX $\quad \alpha, \alpha^{\prime}$-dichloro-p-xylene

DI Deionized

DMAc N,N-dimethylacetamide

DMF Dimethylformamide

DMSO Dimethyl sulfoxide

EA Ethyl acetate

EDA Ethylenediamine

GA Glutaraldehyde

GO Graphene oxide

HDA Hexanediamine

HF Hollow fiber

HMDI Hexamethylene diisocyanate

HVNC High-value natural compound

IP Interfacial polymerization

IPA Isopropanol

ISA Integrally skinned asymmetric

LBL Layer-by-layer

MEK Methyl ether ketone

$\mathrm{MeOH} \quad$ Methanol

MMM $\quad$ Mixed matrix membrane

MOF Metal-organic framework

MPD m-phenylamine

MW Molecular weight

MWCNT Multi-walled carbon nanotube

MWCO Molecular weight cut-off

NIPS Non-solvent induced phase separation

NF Nanofiltration

NMP N-methyl pyrrolidone

OSN Organic solvent nanofiltration

PA Polyamide

PAA Poly(acrylic acid)

PAI Polyamide-imide

PAN Polyacrylonitrile

PAN-H Hydrolyzed polyacrylonitrile

PANi Polyaniline

PBI Polybenzimidazole

PDDA Poly(diallyldimethylammonium chloride)

PDMS Polydimethylsiloxane

PE Polyelectrolyte

PEC Polyelectrolyte complex

PEEK Poly(ether ether ketone) 
PEEKWC Poly(oxa-p-phenylene-3,3-phtalido-p-phenylenxoxa-p-phenylenoxoxy-pphenylene) with Cardo group

PEG Polyethylene glycol

PEI Polyetherimide

PHC Polymeric homogeneous composite

PI Polyimide

PIM Polymer of intrinsic microporosity

PPSU Polyphenylsulfone

PPy Polypyrrole

PS Polystyrene

PSf Polysulfone

PSS Poly(sodium styrene sulfonate)

PTMSP Poly[1-(trimethylsilyl)-1-propyne]

PVDF Poly(vinylidene fluoride)

PVS Poly(vinyl sulfate)

PWP Pure water permeability

RB Rose bengal

rGO Reduced graphene oxide

SPEEK Sulfonated poly (ether ether ketone)

SRNF Solvent-resistant nanofiltration

TBPEEK Modified PEEK with tertiary butylhydroquinone

TFC Thin film composite

TFN Thin film nanocomposite

THF Tetrahydrofuran

TMC Trimesoyl chloride

TTSBI 5,5',6,6'-tetrahydroxy-3,3,3',3'-tetramethylspirobisindane

VAPEEK PEEK with valeric acid group

XDA p-xylylenediamine 


\begin{abstract}
Solvent-resistant nanofiltration (SRNF) is an emerging membrane-based separation technology that can separate molecules of 200-1000 Da in various organic solvents efficiently. It has the potential to replace or be combined with traditional separation processes in industry to lower energy consumption and reduce waste. As hollow fiber membranes can offer advantages over flat sheet membranes and are not known to be commercially available for SRNF applications, this study aims to develop hollow fiber membranes that can perform nanofiltration in challenging polar aprotic solvents such as dimethylformamide (DMF) at a lower operating pressure than existing SRNF membranes.

Polyamide-imide hollow fibers were fabricated by non-solvent induced phase separation and crosslinked using 3-aminopropyl trimethoxysilane (APTMS) so that they were stable in DMF. The crosslinked membranes were characterized by their gel content, swelling property, contact angle and mechanical properties. A conditioning treatment with either isopropanol (IPA) or deionized (DI) water was found to affect the morphology and performance of the membranes. Nanofiltration tests were carried out under 2 bar using Rose Bengal (1017 Da) in IPA and DMF. The membranes were tested in continuous operation for 7 days and stable performance in terms of flux and rejection could be attained, showing their potential to be applied in SRNF processes effectively.
\end{abstract}




\section{CHAPTER 1 - Introduction}

\subsection{Background}

Rising global energy consumption and the threat of depletion of fossil fuels have led to greater urgency to develop sustainable technologies that are energy- and cost-efficient. In the field of separation technology, membrane-based separation occupies an important role as a potentially cost-effective, flexible and compact process. Nanofiltration (NF) is a pressure-driven membrane separation process that rejects molecules in the 200-1000 Da range, filling the gap in separation performance between ultrafiltration and reverse osmosis. NF membranes typically have a narrow pore size distribution in which pore diameters fall in the range $0.5-2 \mathrm{~nm}$ and have been widely used to remove divalent ions for water softening, as well as small organic molecules e.g. micropollutants, sugars and dyes from water (Mulder 2006). While industrial applications of NF membranes in aqueous solutions have been established, their development for separation processes in organic media is still in the early stage and has been gaining attention since the late 1990s. Such membranes are termed as organic solvent nanofiltration (OSN) or solvent-resistant nanofiltration (SRNF) membranes.

SRNF is an emerging technology that can separate molecules of 200-1000 Da in organic solvents in an efficient manner (Vandezande, Gevers et al. 2008). There are many potential advantages of employing SRNF in industrial separation processes. As no phase transitions are involved, it can provide a sustainable alternative for energy-intensive processes such as evaporation and distillation by lowering energy consumption considerably (Silva, Peeva et al. 2008). The milder operating conditions of SNRF can minimize the thermal damage or potential degradation of sensitive molecules. Recycling of solvents and reagents accomplished by SRNF can reduce the loss of valuable resources and minimize the quantity of waste generated in processes such as extractions, chromatography and recrystallizations. SRNF can be operated as a continuous process and be combined with existing separation technologies to form a hybrid process due to its modular set-up (Vandezande, Gevers et al. 2008). With these unique advantages, SRNF is envisioned to have broad application potential in many kinds of industry including petrochemical, food, pharmaceutical and fine chemical industries, serving as a green engineering process as well as an effective tool for process intensification. Several studies have successfully demonstrated the feasibility of utilizing SRNF in the recovery of homogeneous catalysts (Luthra, Yang et al. 2002, Scarpello, Nair et al. 2002, Aerts, Weyten et al. 2004), the solvent exchange in multi-step chemical reactions (Livingston, Peeva et al. 2003, Sheth, Qin et al. 2003), the purification of 
high-value natural compounds (HVNCs) or active pharmaceutical ingredients (APIs) (Sereewatthanawut, Lim et al. 2010, Vanneste, Ormerod et al. 2013), the solvent recovery in chemical processes (Darvishmanesh, Firoozpour et al. 2011, Rundquist, Pink et al. 2012) and the separation of ionic liquids (Van Doorslaer, Glas et al. 2010).

\subsubsection{Challenges}

The most critical challenge for the practical application of SRNF is to develop membranes that have an excellent stability in organic solvents and thus show a reliable performance in long-term operation. Other desired membrane properties include film processability, mechanical strength, thermal resistance, material availability and cost (Jansen, Darvishmanesh et al. 2013). Although ceramic membranes that are typically prepared from metal oxides including titania $(\mathrm{TiO} 2)$, alumina $\left(\mathrm{Al}_{2} \mathrm{O}_{3}\right)$ or zirconia $\left(\mathrm{ZrO}_{2}\right)$ can provide good selectivity and chemical and thermal stability, they suffer from brittleness and producing them on a large-scale remains complicated and expensive (Guizard, Ayral et al. 2002). Furthermore, due to the intrinsic hydrophilicity of the materials, low permeation flux of nonpolar solvents is commonly observed. As a result, inorganic membranes exhibit limited applications and remain less widespread than their polymeric counterpart despite several studies on inorganic membranes for SRNF (Tsuru, Miyawaki et al. 2003, Tsuru, Narita et al. 2008, Dobrak, Verrecht et al. 2010, Buekenhoudt, Bisignano et al. 2013). The majority of SRNF membranes are made from polymeric materials as they provide a wide choice of materials, cost-effectiveness, excellent processability, good reproducibility and flexibility in tailoring membrane properties for different applications. However, the key drawbacks of polymeric membranes are their limited stability in solvents and at high temperature.

NF membranes that were designed for aqueous systems faced many difficulties in organic solvents such as excessive swelling or dissolution of polymeric membrane materials in certain organic solvents, thus hindering their application. In the past decade, significant progress has been made to improve the stability of polymeric membranes, as shown by the recent successful development of solvent-stable materials that feature excellent chemical stability in various organic solvents which include challenging solvents like N-methyl pyrrolidone (NMP) and dimethylformamide (DMF) (See Toh, Lim et al. 2007). Currently, there are few commercial SRNF membranes in the market. Their performance in terms of solvent permeability and solute rejection can be improved further for a wider range of implementations in real industrial processes. Thus, there is an ongoing need to develop novel 
membranes that involves designing and controlling the membrane nanostructure to enable high solvent permeabilities together with acceptable solute rejections.

Currently, most lab-scale studies are on flat sheet membranes and commercial SRNF membranes consist of a few spiral-wound modules and flat sheet membranes. There are no hollow fiber SRNF membranes known to be commercially available and literature is also relatively scarce on their preparation. In general, the hollow fiber membrane configuration can provide certain advantages compared to flat sheet membranes, such as a higher membrane area to module volume ratio, elimination of the need for spacers and ease of scaling up as modules are simpler and more compact (Dutczak, Tanardi et al. 2012). Furthermore, the testing of flat sheet membranes is usually carried out at high operating pressures ranging from 10 to $30 \mathrm{bar}$, while hollow fiber membranes can be tested at 5 bar or lower. Hence, more studies can be undertaken to improve the property and performance of hollow fiber membranes for SRNF since they have the potential to make SRNF a more efficient and thus attractive separation process.

\subsection{Objectives}

This study aims to develop hollow fiber membranes with good solvent stability for SRNF application and hopes to achieve the following objectives:

$>$ Choosing a suitable polymeric material and fabricating hollow fiber substrates with the desired morphology by non-solvent induced phase separation (NIPS) method via dry-jet wet spinning technique;

$>$ Improving the long-term chemical stability of the substrates in target solvents by investigating chemical modification techniques and understanding their mechanisms;

$>$ Evaluating the solvent permeabilities and solute rejections of the hollow fiber membranes under a lower operating pressure than that in previous studies, and monitoring their long-term performance.

\subsection{Thesis outline}

The thesis consists of four chapters. Chapter 1 is an introduction to the background of solvent-resistant nanofiltration, existing challenges and research objectives. Chapter 2 
provides a literature review on the various strategies used in developing state-of-the-art polymeric membranes intended for SRNF applications. Chapter 3 presents the fabrication and modification of hollow fiber substrates, and the results of their filtration performance in the target solvents and solutes under low operating pressure. Chapter 4 gives conclusions of this study and recommendations for future work. 


\section{CHAPTER 2 - Literature Review}

\subsection{Mass transfer in polymeric SRNF membranes}

Establishing a general model to describe the mass transfer process in SRNF membranes remains a challenge due to various physical and chemical factors including membranesolvent, solute-solvent and solute-membrane interactions which all contribute to complicate the mass transfer process. Several studies on the solvent transfer mechanism were conducted by Darvishmanesh et al. who identified the most important factors influencing solvent permeability - solvent polarity (dielectric constant), solvent viscosity, solubility parameter, surface tension and molar volume. They developed a model which assumes that solvent is transported through solution-diffusion as well as convectively through membrane pores without any change in concentration. It correlated well with experimental results over a wide range of solvents, thus validating the assumption (Darvishmanesh, Buekenhoudt et al. 2009, Darvishmanesh, Buekenhoudt et al. 2009, Darvishmanesh, Degreve et al. 2010).

\subsubsection{Factors influencing solvent transfer}

It was found that the flux of solvents with higher polarity increased in hydrophilic membranes but decreased in hydrophobic membranes (Van der Bruggen, Geens et al. 2002). Compared to solvent polarity, solvent viscosity seems to play a more predominating effect (Geens, Peeters et al. 2005), with solvent permeability decreasing dramatically with higher solvent viscosity (Machado, Hasson et al. 1999, Machado, Hasson et al. 2000, Bhanushali, Kloos et al. 2001, Geens, Van der Bruggen et al. 2006). Darvishmanesh et al. also stated that in porous SRNF membranes, the solvent viscosity is a major parameter affecting solvent transport (Darvishmanesh, Degrève et al. 2009, Darvishmanesh, Degreve et al. 2010). The difference between the surface tension of solvents and membranes is related to their mutual affinity, with a low difference indicating strong affinity leading to higher solvent permeability (Machado, Hasson et al. 2000, Geens, Van der Bruggen et al. 2006). The effect of molar volume, which is indicative of the size of the solvent, has not been consistent as studies have reported increasing solvent flux with higher solvent molar volume (Bhanushali, Kloos et al. 2001, Geens, Van der Bruggen et al. 2006), while it did not have any significant effect in another (Vankelecom, De Smet et al. 2004). Strong interactions between the membrane material and solvent can result in swelling and reorganization of the membrane's molecular structure, affecting solvent permeability significantly (Van der Bruggen, Geens et al. 2002, Darvishmanesh, Degrève et al. 2010). A few studies have correlated solvent permeability to the swelling/viscosity (Vankelecom, De Smet et al. 2004, Stamatialis, Stafie 
et al. 2006, Dobrak-Van Berlo, Vankelecom et al. 2011). However, as the swelling phenomenon is physicochemically complex, established models have yet to account for swelling and allow accurate prediction of its effect on solvent permeability.

\subsubsection{Factors influencing solute transfer}

The most significant factors influencing the transport of solutes are the solute properties such as molecular size, charge and polarity, the membrane properties, the solvent-solute interactions and solvent-membrane interactions (Cheng, Zhang et al. 2014). Rejection generally increases with increasing solute molecular size. Membranes with a negatively charged polyelectrolyte active layer rejected more of a negative dye than positively charged dyes (Li, De Feyter et al. 2008), indicating the role of Donnan effects in influencing the separation of charged solutes. The membrane pore structure, surface charge and affinity with solutes also affect the solute transport process. Negative rejections were reported by polydimethylsiloxane (PDMS) membranes in which the solute flux was higher than that of the solvent because of strong interaction effects between the solute and membrane (Bhanushali, Kloos et al. 2002). This indicates that lower rejections can be expected for membranes that exhibit strong affinity with the solute (Darvishmanesh, Degreve et al. 2010). Solute-solvent coupling effects should also be considered as solvation and hydration processes will influence the molecular size of the solute (Bhanushali, Kloos et al. 2002). Since swelling may reorganize the membrane material and cause pore structure variations, solute rejections may be affected. Swelling causes the free volume in dense membranes to increase, resulting in lower rejections, while the narrowing of pores in porous membranes leads to increased rejections (Geens, Van der Bruggen et al. 2004). Some studies also reported that membrane swelling increased solvent flux dramatically while having no significant effect on the solute rejection (Tarleton, Robinson et al. 2006).

\subsection{Development of polymer-based SRNF membranes}

There are generally four approaches to design polymer-based SRNF membranes. Integrally skinned asymmetric (ISA) membranes comprise of a skin layer on a more porous support made of the same material, while in thin film composite (TFC) membranes, the skin layer and porous support are made from different materials. The skin layer is selective for solutes while the sublayer serves as mechanical support and provides resistance against compaction. Recently, there is also an emerging trend in enabling nanomaterials for SRNF. In general, nanomaterials such as gold or silicon dioxide nanoparticles, zeolites, metal-organic 
frameworks (MOFs), graphene oxide (GO) nanosheets and multi-walled carbon nanotubes (MWCNTs) are integrated either in the polymer matrix or the separation layer to yield mixed matrix membranes (MMMs) or thin film nanocomposite (TFN) membranes, respectively. Each of these strategies will be reviewed in the following subsections.

\subsubsection{Integrally skinned asymmetric membranes}

ISA membranes are usually prepared from a phase inversion process which involves casting a thin film of homogeneous polymer solution and immersing it in a non-solvent coagulation bath for inducing solvent/non-solvent exchange to form an asymmetric membrane structure (Peeva, Sairam et al. 2010). Sometimes, a short duration for solvent evaporation is introduced to increase the local polymer concentration on the membrane surface. Essentially, the final membrane morphology and its permeability and rejection performance are determined by the thermodynamics of the phase inversion and the kinetics of the solvent/non-solvent exchange (Mulder 2006, Vandezande, Gevers et al. 2008).

The polymeric materials that have been used to fabricate ISA membranes for SRNF are listed in Table 1. Generally, polymers with higher rigidity have greater stability in solvents. The presence of aromatic groups or imide bonds in the backbone can increase the solventresistance property of the polymer (Vandezande, Gevers et al. 2008). Polyimides (PIs) are the most widely used materials owing to their high chemical resistance, good thermal stability and mechanical strength. Unfortunately, these membranes are also susceptible to solvents interaction with the polymer chains. To improve their anti-swelling property and chemical and mechanical stability, polymer chains can be crosslinked giving rise to stable 3-d network structures.

State-of-the-art PI membranes for SRNF are crosslinked by diamines either during phase separation (Vanherck, Cano-Odena et al. 2010) or post-synthetically (See Toh, Lim et al. 2007, Vanherck, Vandezande et al. 2008). The general reaction mechanism illustrated in Figure 1 involves the breaking up of the imide rings in the polymer backbone to form amide bonds at both ends of the diamine, thus two polymer chains are linked to each other (Vanherck, Koeckelberghs et al. 2013). Lenzing P84 ${ }^{\circledR}$ membranes showed good chemical stability in DMF, NMP, tetrahydrofuran (THF) and dichloromethane (DCM) after being crosslinked in methanol solutions containing aliphatic diamines (See Toh, Lim et al. 2007). Here, methanol was used to swell the polymer chains and allow crosslinker to diffuse into 
the membrane to ensure a complete and uniform crosslinking of the entire membrane (Liu, Wang et al. 2001). An aromatic diamine, p-xylylenediamine (XDA), was used as a crosslinker to imbue an asymmetric Matrimid® membrane with good stability towards NMP, DMF, dimethyl sulfoxide (DMSO) and N,N-dimethylacetamide (DMAc) (Vanherck, Vandezande et al. 2008).

However, such post-synthetic crosslinking approach not only takes a long reaction time but also consumes a large amount of extra solvent. Thus, an alternative approach was to add the crosslinker directly to the non-solvent coagulation bath so that membrane solidification and chemical crosslinking could take place simultaneously. Hendrix et al. applied this method on Matrimid® 5218 membranes using XDA, ethylenediamine (EDA) and 1,6hexanediamine (HDA) (Hendrix, Vanherck et al. 2012). It was found that membranes crosslinked with XDA exhibited excellent rejection (> 95\%) of Rose Bengal (RB) and low permeability of DMF $\left(<1 \mathrm{~L} \mathrm{~m}^{-2} \mathrm{~h}^{-1} \mathrm{bar}^{-1}\right)$. In contrast, HDA-crosslinked membranes showed high DMF permeability up to $10 \mathrm{~L} \mathrm{~m}^{-2} \mathrm{~h}^{-1}$ bar $^{-1}$ but with moderate rejections of $\sim 85 \%$. Although chemical crosslinking with diamines improves the stability of PI membranes, the possibility of re-imidization leading to loss of crosslinking of the PI should be considered when the membranes need to be exposed to high temperatures (See Toh, Lim et al. 2007).
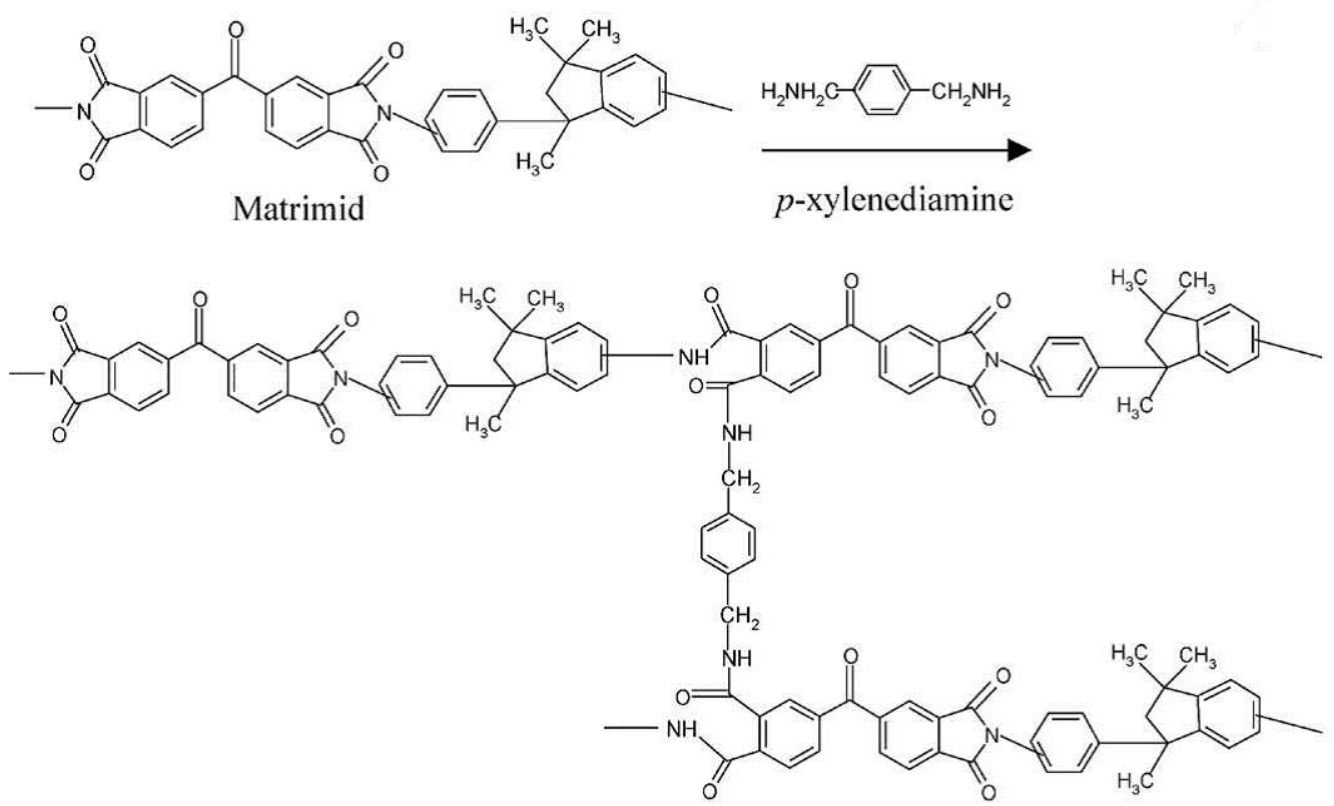

Figure 1. Mechanism of crosslinking of Matrimid ${ }^{\circledR}$ with p-xylenediamine (Tin, Chung et al. 2003) 
Table 1. Polymers used to prepare ISA SRNF membranes

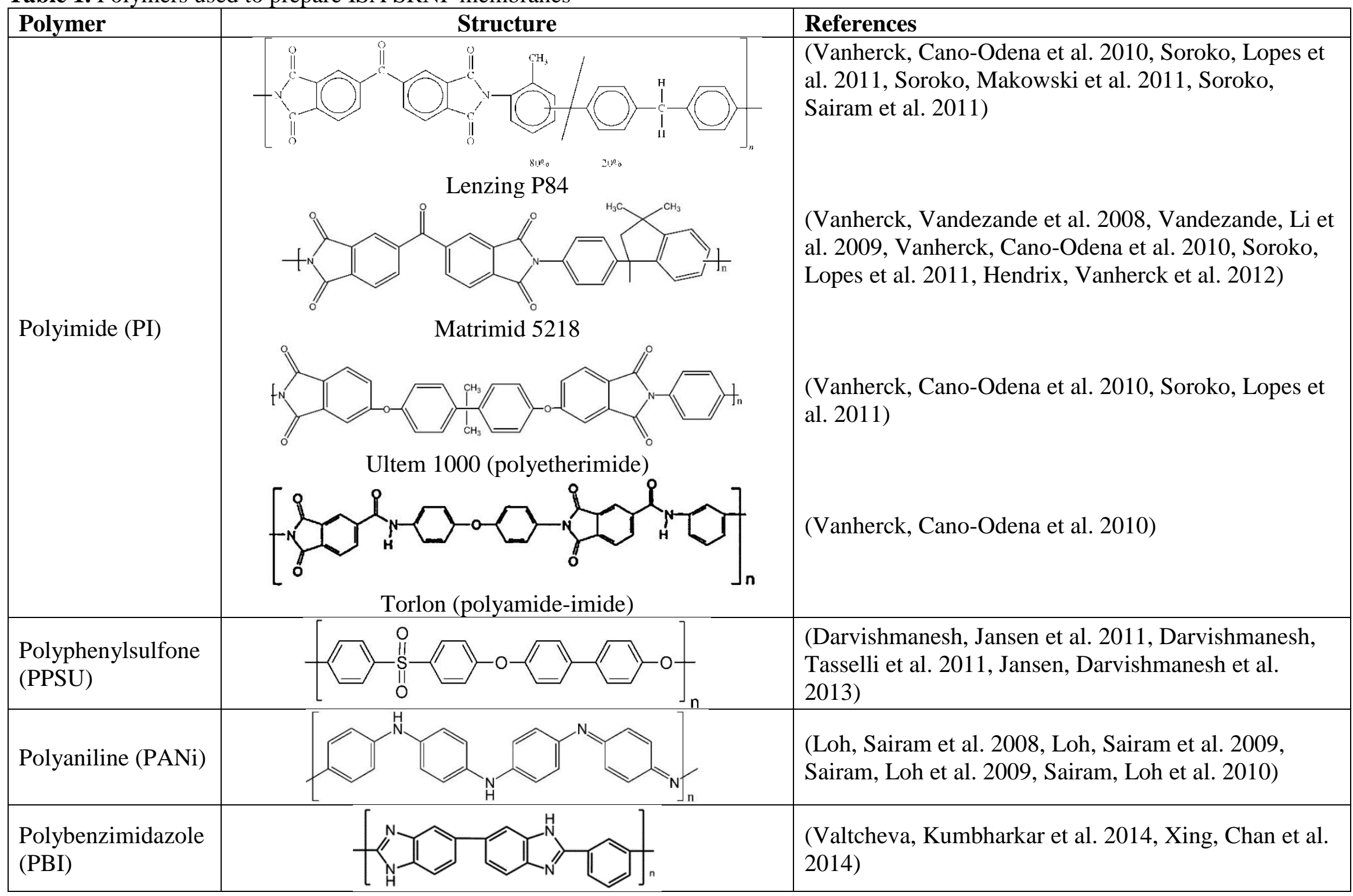


In addition, the impact of fabrication parameters on the SRNF performance has also been investigated. Parameters like polymer dope composition, choice of PI, solvent evaporation time and the effect of co-solvent have been studied to date (See-Toh, Silva et al. 2008, Soroko, Lopes et al. 2011, Soroko, Makowski et al. 2011, Soroko, Sairam et al. 2011). Key takeaways include low fluxes and rejections for membranes made from Matrimid ${ }^{\circledR} 5218$ and polyetherimide (PEI, Ultem ${ }^{\circledR}$ 1000) as compared to that of P84®, flux decline without significant effect on the rejection when a solvent evaporation step was applied in the fabrication of a $\mathrm{P} 84{ }^{\circledR} / \mathrm{DMF} / 1,4-$ dioxane system, high rejection in the NF range when a membrane skin layer was formed through the addition of a co-solvent, and realizable defectfree membranes with sufficient mechanical strength when 35,000 Da or higher molecular weight (MW) PIs were used. Nevertheless, these effects are specific to the polymer/solvent/non-solvent system and should not be over-generalized or taken for granted.

Apart from using diamines, polyamide-imide (PAI, Torlon $囚)$ membranes were successfully crosslinked using diisocyanates (Dutczak, Cuperus et al. 2013). Specifically, commercial PAI membranes from SolSep B.V. were treated with hexamethylene diisocyanate (HMDI) to allow crosslinking between the amide group in the PAI backbone and the isocyanate functional group in HMDI. After crosslinking, the membranes showed good mechanical properties and were resistant to NMP. Re-imidization was not observed at $120{ }^{\circ} \mathrm{C}$ although further investigations beyond this temperature are needed. In principle, chemical crosslinking is applicable to other polymers as long as the appropriate functional groups are present. Another promising candidate for SRNF membrane fabrication is polybenzimidazole (PBI). Recent works by Valtcheva et al. have shown that PBI membranes crosslinked with $\alpha, \alpha$ '-dibromo-p-xylene (DBX) were stable not only in polar aprotic solvents but also in strongly acidic and basic environments which opened up opportunities for membrane separations under corrosive conditions (Valtcheva, Kumbharkar et al. 2014, Valtcheva, Marchetti et al. 2015).

Apart from chemical crosslinking, other means of crosslinking ISA membranes have also been reported. Thermal crosslinking of polyaniline (PANi) membranes, by treating them at $180^{\circ} \mathrm{C}$ in air to induce crosslinking of the polymeric chains as well as the oxidation of PANi, were reported to strengthen the stability of membranes in solvents such as acetone, methanol, DMF, NMP and THF (Loh, Sairam et al. 2008, Loh, Sairam et al. 2009, Sairam, Loh et al. 2009, Sairam, Loh et al. 2010). However, crosslinking the membranes thermally can reduce 
the membrane porosity, resulting in a decrease in flux. Alternatively, chemical crosslinking with $\alpha, \alpha^{\prime}$-dichloro-p-xylene (DCX) or glutaraldehyde (GA) can achieve the same solvent stability while enhancing the compaction resistance of the crosslinked PANi membranes to give higher solvent fluxes as compared to the thermally crosslinked ones. Besides thermal crosslinking, UV curing is also employed to enhance the chemical stability of PI and polysulfone (PSf) membranes (Struzynska-Piron, Loccufier et al. 2013). In the case where penta-acrylate was used as a crosslinker for PSf membrane, higher solvent stability was obtained at the expense of the isopropanol (IPA) permeability (Struzyńska-Piron, Bilad et al. 2014). The IPA permeability decreased significantly from 3.3 to $0.07 \mathrm{~L} \mathrm{~m}^{-2} \mathrm{~h}^{-1}$ bar $^{-1}$ after UV irradiation induced penta-acrylate crosslinking with the PSf polymer chain. This was due to the densification of the membrane top layer.

In the quest for novel materials for SRNF membranes, polymer blending has been explored as a relatively simple and reproducible strategy to chemically modify or tailor polymers (Jansen, Darvishmanesh et al. 2013). For example, charged membranes prepared by blending sulfonated poly (ether ether ketone) (SPEEK) with PSf were used for separating dyes in various alcohols (Li, De Feyter et al. 2008). Neat polyphenylsulfone (PPSU) has also been used to fabricate SRNF membranes owing to its higher impact and chemical resistance than PSf and PEI (Darvishmanesh, Jansen et al. 2011, Darvishmanesh, Tasselli et al. 2011). They were stable in alcohols and alkanes but not resistant to acetone, toluene and methyl ethyl ketone. Blending PPSU with Matrimid® 5218 improved the solvent stability of the membranes significantly (Jansen, Darvishmanesh et al. 2013).

Recently, Koh et al. fabricated carbon molecular sieve (CMS) hollow fiber membranes with solvent resistance towards organic solvents such as benzene, toluene and various isomers of ethylbenzene and xylene. (Koh, McCool et al. 2016) Although CMS is not polymer-based, it is noteworthy that the membranes were derived from a polymeric poly(vinylidene fluoride) (PVDF) counterpart. Interestingly, they proposed a XDA crosslinking method similar to that as aforementioned to prevent the micro and mesopores from collapsing when the hollow fiber membranes were subjected to pyrolysis at temperature ranging from 450 to $550{ }^{\circ} \mathrm{C}$. As a result, the CMS membranes exhibited excellent SRNF performances with order-ofmagnitude increase in flux (relative to zeolite membranes) while maintaining paraxylene/ortho-xylene selectivity of $\sim 100$ with separation factors approaching 4.3. 


\subsubsection{Thin film composite membranes}

The key advantage of TFC membranes lies in the versatility of tuning the chemistry of the selective layer and porous substrate separately to optimize the entire membrane performance (Mulder 2006). As such, they can potentially achieve better performance than ISA membranes by forming much thinner skin layers through means such as interfacial polymerization, plasma polymerization, in situ polymerization, solvent casting, dip- or spincoating and layer-by-layer (LBL) deposition.

\subsubsection{Interfacial polymerization}

In interfacial polymerization (IP), a polymeric support layer is first impregnated in an aqueous solution of m-phenylamine (MPD) monomers before it is placed in an organic phase containing the crosslinker, trimesoyl chloride (TMC). By the reaction between the two monomers, a thin selective layer of polyamide (PA) network is quickly formed on the surface of the porous support membrane. By carefully selecting the solvents and reactive monomers as well as controlling conditions like reaction time and monomer concentrations, the skin layer can be tailored. IP is a technique used in fabricating reverse osmosis and NF membranes for aqueous phase separations and is also commonly used for SRNF membranes due to the wide range of solvent stability of the crosslinked PA.

Jimenez Solomon et al. prepared TFC membranes by IP on a solvent-stable crosslinked P84 PI support. The membranes showed higher permeability in DMF, THF and acetone than the commercial SRNF membrane DuraMem® ${ }^{\circledR} 150$ at comparable solute rejections (Jimenez Solomon, Bhole et al. 2012). It was found that solvent fluxes can increase further by impregnating the crosslinked PI substrate with polyethylene glycol before performing IP and treating the membrane with DMF after the IP reaction. DMF was described as an 'activating solvent' that served to remove some of the loose polyamide structures in the top layer so as to reduce the resistance to solvent permeation. In a subsequent study, the TFC membranes prepared by IP were treated with hydrophobic reagents having an amino group that can react with the unreacted acyl chloride groups on the membrane surface (Jimenez Solomon, Bhole et al. 2013). Introduction of fluorine and silicon in the polyamide selective layer increased permeabilities of non-polar solvents such as ethyl acetate and toluene significantly. This suggests that surface chemistry plays a significant role in governing the mass transport through the PA selective layer. As an attestation, Zhang et al. formed a hydrophilichydrophobic hybrid layer over a polyacrylonitrile (PAN) substrate. The substrate was first 
dip-coated with aqueous polyethyleneimine before bringing into contact with a solution containing hydroxyl terminated trifluoride PDMS and TMC. Polyethyleneimine and PDMS was crosslinked by TMC to afford TFC membranes with good resistance to both polar and non-polar solvents, including IPA, butanone, ethyl acetate and n-heptane, as evidenced by negligible swelling of the membranes in the solvents (Zhang, Zhang et al. 2014).

Besides the chemistry of the PA layer, the thickness plays a more direct role in determining the mass transport through the selective layer. Recently, Karan et al. synthesized freestanding PA nanofilms with thickness less than $10 \mathrm{~nm}$ using a sacrificial layer of cadmium hydroxide nanostrands (Figure 2a) (Karan, Jiang et al. 2015). The results showed

high methanol permeability in the range of $11.0-12.0 \mathrm{~L} \mathrm{~m}^{-2} \mathrm{~h}^{-1} \mathrm{bar}^{-1}$. As the concentration of MPD increased, crumpling of the nanofilm occurred which further improved methanol permeability up to $\sim 52.0 \mathrm{~L} \mathrm{~m}^{-2} \mathrm{~h}^{-1}$ bar $^{-1}$ without compromising the membrane selectivity. This was due to the crumpled nanofilms having a larger surface area. Similarly, Jimenez Solomon et al. created ultrathin polyarylate nanofilms down to the thickness of $20 \mathrm{~nm}$ on the top of crosslinked P84 PI supports (Jimenez-Solomon, Song et al. 2016). They reported methanol permeability of $6.0-8.0 \mathrm{~L} \mathrm{~m}^{-2} \mathrm{~h}^{-1} \mathrm{bar}^{-1}$ when using monomers such as cardostructured 9,9-bis(4-hydroxyphenyl)fluorene (BHPF) and spiro-structured 5,5',6,6'tetrahydroxy-3,3,3',3'-tetramethylspirobisindane (TTSBI). In addition to the low thickness, the high permeability was accredited to the use of contorted monomers which introduced intrinsic microporosity and interconnectivity within the nanofilms (Figure 2b).

\subsubsection{Solution coating}

A polymer solution can be coated on a support to prepare TFC membranes. Methods include using a casting knife, pouring the solution over the tilted support, or dip-coating (Schäfer, Fane et al. 2005). PDMS is one of the most studied coating materials for preparing TFC SRNF membranes (Stafie, Stamatialis et al. 2005, Aerts, Vanhulsel et al. 2006, Gevers, Aldea et al. 2006, Gevers, Vankelecom et al. 2006). Crosslinked PDMS has been reported as chemically stable in some organic solvents and its low polarity makes it preferred for use in apolar solvents. The thickness and crosslinking density of the PDMS selective layer are the two major parameters for controlling solvent flux and membrane selectivity. A major problem with PDMS is the swelling of the polymer in apolar solvents. However, this can be reduced by the addition of fillers which will be described in section 2.2.3. Other polymers such as polyurethane (Florian, Modesti et al. 2007), polypyrrole (PPy) (Li, Vandezande et 
al. 2008, Shao, Cheng et al. 2014) and poly[1-(trimethylsilyl)-1-propyne] (PTMSP) (Volkov, Parashchuk et al. 2009) have also been studied as coating materials on polymeric supports.
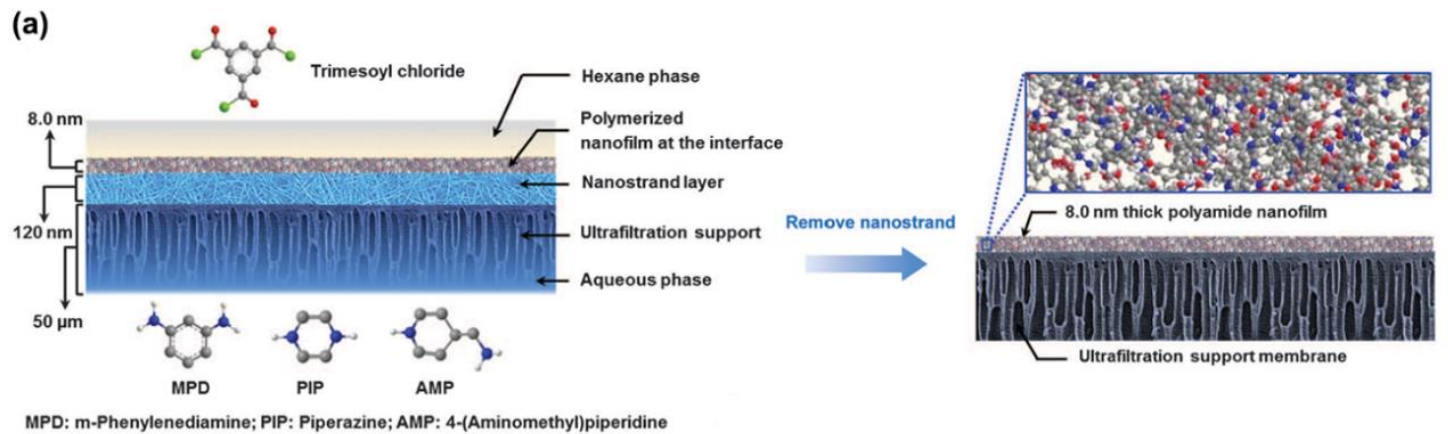

(b)

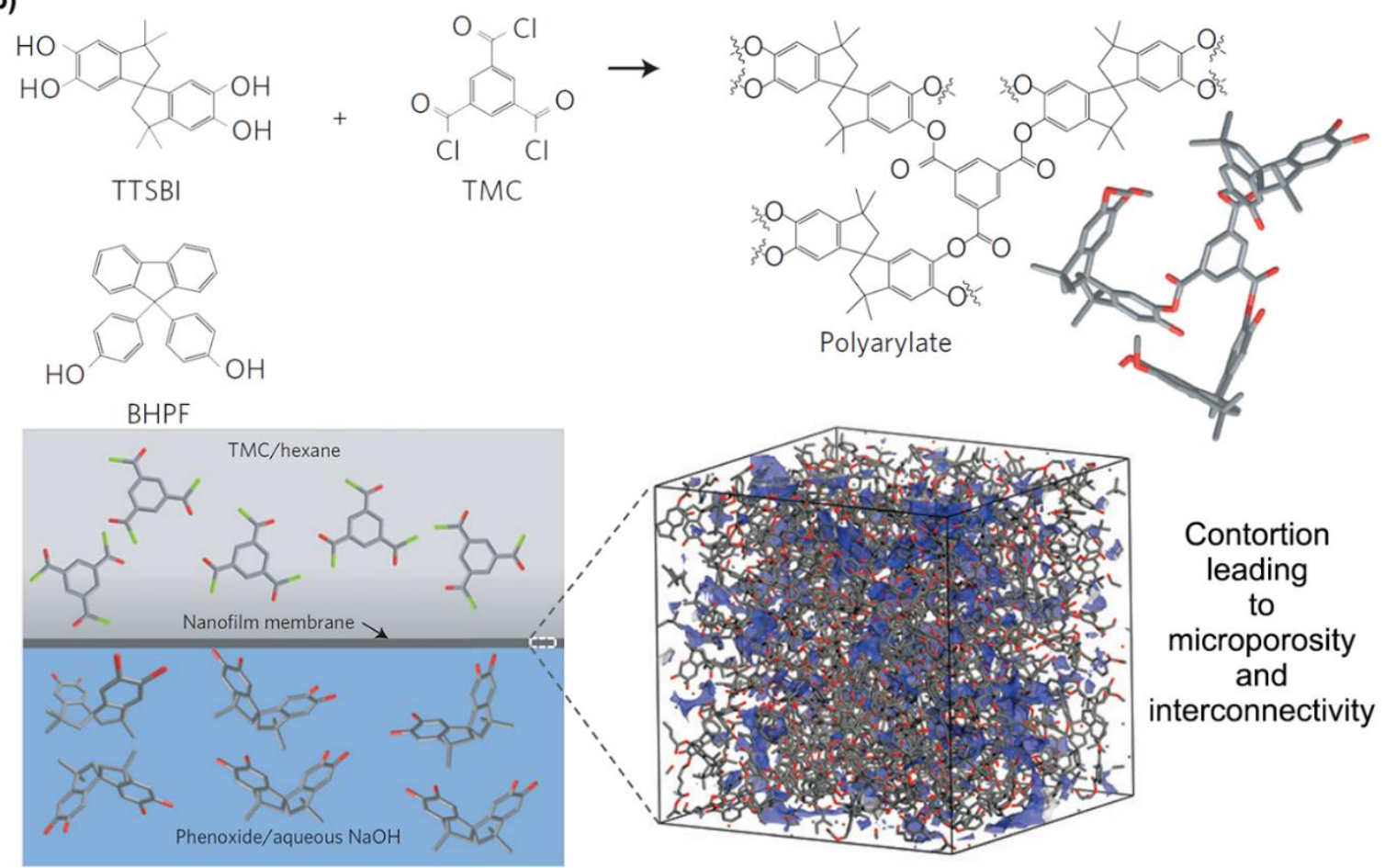

Figure 2. Schematic illustrations of the IP reaction to give (a) nanofilm of sub-10 $\mathrm{nm}$ in thickness using sacrificial cadmium hydroxide nanostrand layer (Karan, Jiang et al. 2015);

(b) nanofilm using contorted monomers such as BHPF and TTSBI leading to microporosity and interconnectivity within the PA nanofilm (Jimenez-Solomon, Song et al. 2016)

Polymers of intrinsic microporosity (PIMs), a new class of polymers containing interconnected micropores formed by rigid and contorted polymer chains, have shown a good potential for SRNF (Budd, Ghanem et al. 2004, McKeown 2012). TFC membranes that comprise of PIM and PIM-1 copolymers on PAN supports were synthesized with promising separation performances especially for n-heptane with permeability as high as 
18.0 $\mathrm{L} \mathrm{m}^{-2} \mathrm{~h}^{-1}$ bar $^{-1}$ and rejection of hexaphenylbenzene up to $97 \%$ (Fritsch, Merten et al. 2012, Gorgojo, Karan et al. 2014). The solvent stability of these TFC PIM/PAN membranes can also be enhanced by chemical or thermal crosslinking. Another promising class of materials is the block copolymers that can be self-assembled into various well-defined nanostructures (Kim, Yang et al. 2010). For example, polystyrene-block-poly(ethylene oxide) diblock copolymer blended with poly(acrylic acid) homopolymer can be deposited as a selective layer on a porous support by spin- or dip-coating (Li, Fustin et al. 2010). Following which, UV irradiation can be used to crosslink the polystyrene (PS) phase to create an interpenetrated network structure that is resistant to DMF, THF and DCM. On top of that, polymeric homogeneous composite (PHC) membranes, in which the top layer and support are prepared from the same material, can be optimized independently for SRNF. Using the same material implies a high affinity between the two layers and reduces the possibility of delamination. As a result, PHC membranes synthesized by coating a P84 PI solution on a diamine-crosslinked P84 support can yield membranes that were completely stable in NMP for over 96 h (Fontananova, Di Profio et al. 2013).

\subsubsection{Layer-by-layer deposition of polyelectrolytes}

This is a versatile approach typically done by depositing polyelectrolytes of opposite charge successively on a charged membrane substrate resulting in a multilayered polyelectrolyte complex (PEC) selective layer stabilized by strong electrostatic interactions. The main advantage of this technique is the ability to offer precise control of the PEC layer thickness by varying the number of deposited bilayers (Zhao, An et al. 2011). Through the careful selection of individual PEC constituents and manipulation of conditions such as the $\mathrm{pH}$ and ionic strength of the PE solutions, the properties of the resulting PEC are tunable for different targeted SRNF.

Multilayered poly(diallyldimethylammonium chloride) (PDDA)/SPEEK membrane prepared on a hydrolyzed PAN (PAN-H) support exhibited an excellent solvent stability in IPA, THF and DMF (Li, De Feyter et al. 2008). It was found that the IPA permeability gradually increased from 0.06 to $0.98 \mathrm{~L} \mathrm{~m}^{-2} \mathrm{~h}^{-1} \mathrm{bar}^{-1}$ with increasing concentration of $\mathrm{NaCl}$ in the PE solutions (Li, Goyens et al. 2010). The addition of salt made the PE conformation more "loopy" or "tailed", resulting in a thicker and looser PEC layer. This increased the solvent flux without compromising selectivity. On the other hand, Ahmadiannamini et al. utilized PDDA with poly(acrylic acid) (PAA) to form the PEC layer (Ahmadiannamini, Li 
et al. 2012). In addition, they paired PDDA with two different polyanions, each either in Naor H-form, to study how the type of polyanion and cationic counter ion affect the membrane performance (Ahmadiannamini, Li et al. 2012). Higher permeabilities and rejections were obtained when polyanions in H-form were used, which were attributed to a loopier PEC layer and higher surface charges. PDDA/SPEEK bilayers were also deposited on a Si/PAN$\mathrm{H}$ composite support (Chen 2013). The rejection of RB in IPA increased from 50\% to $70 \%$ after introducing $\mathrm{SiO}_{2}$ into the PAN-H support. Upon adding of the PE bilayers, the rejection was further increased up to $99 \%$. Furthermore, the membranes also showed good RB rejections in solvents like DMF and THF.

\subsubsection{Mixed matrix membranes}

Polymeric membranes suffer from problems such as the decrease in flux over long-term operation, which is often caused by membrane compaction, and the requirement for preserving agents to prevent pore collapse especially in ISA membranes (Siddique, Rundquist et al. 2014). On the other hand, some inorganic membranes e.g. carbon molecular sieve and zeolite membranes can provide greater permeability and selectivity owing to their well-defined porous structures but are difficult to fabricate and scale-up due to their poor processability (Liu, Kulprathipanja et al. 2008). Thus, the concept of mixed matrix membranes (MMMs) where inorganic materials are incorporated into polymer matrices has been proposed to synergistically combine the merits of these materials. To date, MMMs are widely used for gas separation (Mahajan and Koros 2000), pervaporation (Kariduraganavar, Varghese et al. 2009), desalination (Dong, Qu et al. 2011) and have been employed for SRNF. Some of the common fillers include metal oxides, metal nanoparticles, zeolites, MWCNTs, MOFs, and GO nanosheets (Kim and Van der Bruggen 2010). By the judicious selection of filler-polymer pairs, one can improve selectivity and permeability of existing polymeric membranes (Liu, Kulprathipanja et al. 2008), as well as minimize membrane compaction and excessive swelling. However, difficulties in reproducing MMMs and non-idealities such as poor adhesion between the continuous polymer phase and the fillers can result in interfacial defects, which pose a major challenge to their commercial implementation (Moore and Koros 2005).

PDMS and PI are the common polymers that have been studied for MMM preparation for SRNF. As discussed earlier, PDMS has a tendency to swell especially in non-polar solvents. The free space between polymer chains is increased and solute rejection is compromised 
(Tarleton, Robinson et al. 2005). To overcome this problem, Gevers et al. added ZSM-5 zeolites into PDMS solution before coating it on a PAN support (Gevers, Vankelecom et al. 2005, Gevers, Vankelecom et al. 2006). This decreased the swelling of the PDMS network as the large surface area of ZSM-5 facilitated a crosslinking between the surface silanol groups and the PDMS polymer chains. There was a decrease in the free volume of the PDMS matrix and thus the zeolite-filled membranes showed higher rejection values of the Wilkinson catalyst in various solvents than neat PDMS membrane. Interestingly, the membranes with ZSM-5 showed higher permeability than neat PDMS membrane, indicating that the pores of zeolites provided an additional route to facilitate transport of solvent molecules. To reduce the mass transfer resistance of conventional zeolite fillers, Vanherck et al. incorporated micron-sized hollow spheres of silicalite-1 crystals into PDMS membranes on crosslinked PI supports (Vanherck, Aerts et al. 2010). The resulting MMMs showed higher solvent permeabilities than those containing the regular silicalite- 1 crystals while maintaining similar solute rejections.

$\mathrm{TiO}_{2}$ nanoparticles can also be dispersed in the polymer dope solution to prepare composite organic-inorganic crosslinked PI membranes (Soroko and Livingston 2009). Morphological changes in the membrane were brought about by the incorporation of $\mathrm{TiO}_{2}$. As observed by Soroko and Livingston, the macrovoids in the sublayer of the PI membranes were completely suppressed when $\mathrm{TiO}_{2}$ loading was greater than $3 \mathrm{wt} . \%$. Consequently, the membranes were more resistant to compaction and the impact on solvent permeability and rejection of solute was minimal. In addition, incorporating $\mathrm{SiO}_{2}$ nanoparticles modified by aminopropyldiethoxymethylsilane (APDEMS) within a PEI polymer matrix was found to increase the solvent stability as well as mechanical and thermal resistances of the support membrane (Namvar-Mahboub and Pakizeh 2013). After IP on the support, the TFC membranes exhibited a 95\% rejection of lube oil from a solvent mixture of toluene and methyl ether ketone (MEK) at $5 \mathrm{wt} \% \mathrm{SiO}_{2}$ loading. More importantly, solvent permeability remained relatively constant when the pressure increased from 10 to 20 bar due to enhancement in the compact resistance of the membranes. Another group used 3aminopropyl trimethoxysilane (APTMS) as a crosslinker to prepare Lenzing P84® PI membranes (Siddique, Rundquist et al. 2014). A homogeneous inorganic Si-O-Si network was created throughout the PI membranes, including the skin layer (Figure 3). It was found that membrane compaction was negligible $(<2 \%)$ after crosslinking as the polymer chains were rigidified. However, the solvent permeability was penalized with acetone, DCM and 
DMF permeabilities below $1.0 \mathrm{~L} \mathrm{~m}^{-2} \mathrm{~h}^{-1} \mathrm{bar}^{-1}$ as a result of the diminished fractional free volume of the polymer matrix.
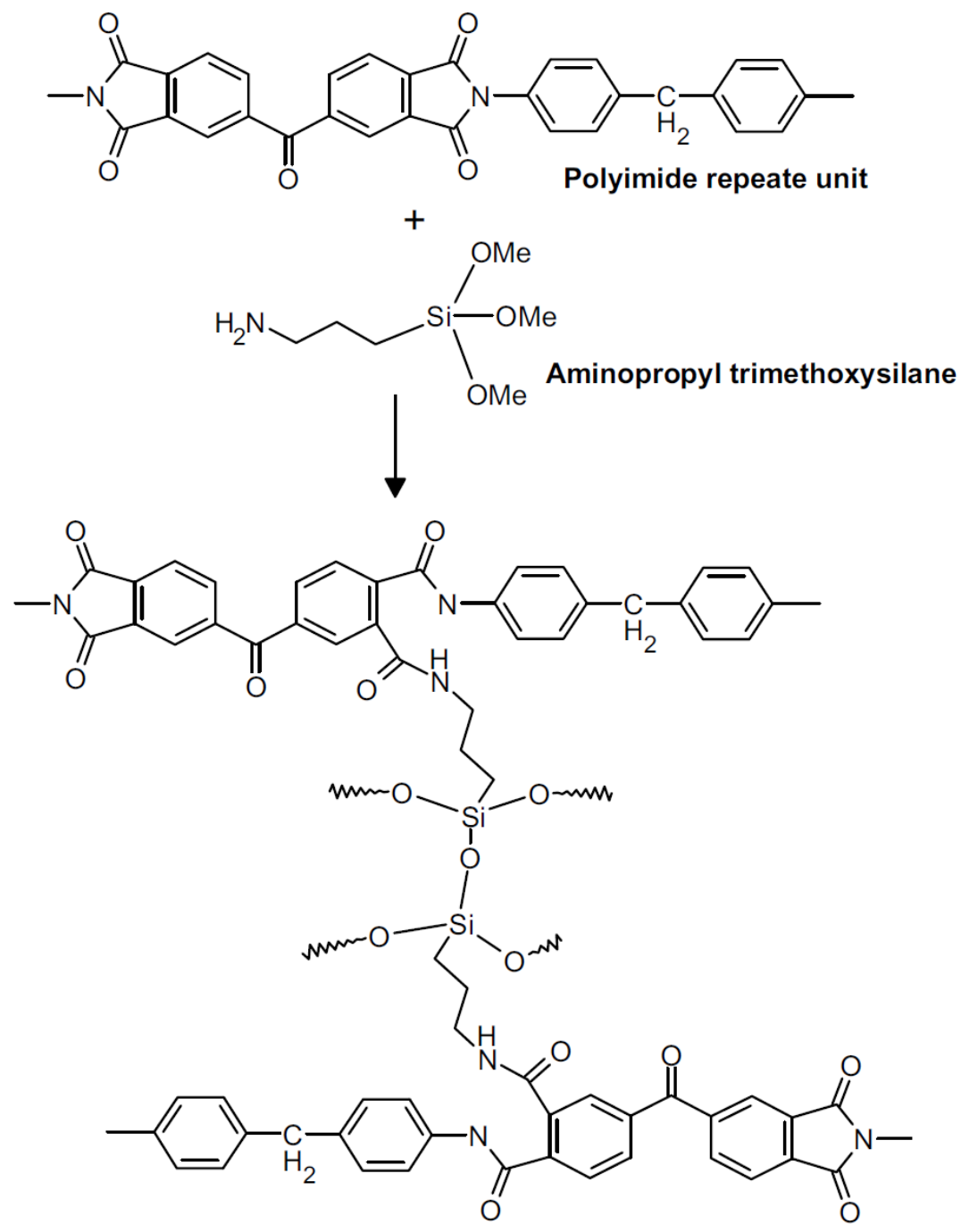

Figure 3. Crosslinking of P84 polyimide with APTMS (Siddique, Rundquist et al. 2014)

MOFs are nanoporous crystalline materials that consist of metal ions connected by various organic ligands via strong coordinative bonds to create 1-d, 2-d and 3-d porous structures (Rowsell and Yaghi 2004). They have attracted much research attention as they possess high porosity and tunable physicochemical properties compared to other nanoporous materials such as zeolites (Zornoza, Tellez et al. 2013). As such, MMMs containing various MOFs have been extensively studied for gas separation (Tanh Jeazet, Staudt et al. 2012) and SRNF applications. Basu et al. incorporated $\mathrm{Cu}_{3}(\mathrm{BTC})_{2}, \mathrm{MIL}-47, \mathrm{MIL}-53(\mathrm{Al})$ and ZIF-8 into PDMS membranes formed on PI support (Basu, Maes et al. 2009). However, morphological observation revealed that voids were formed at the MOF/polymer interface, leading to higher 
permeance of IPA but lower retention of RB due to the non-selective molecular transport through the interfacial defects. To enhance the compatibility between the MOFs and PDMS matrix, N-methyl-N-(trimethylsilyl)-trifluoroacetamide was used to modify the surface of MOF crystals by reacting with the functional groups on the MOF surfaces. As a result, the retention of RB improved from $87 \%$ to $95-98 \%$ for MMMs containing surface modified MOF crystals without sacrificing IPA flux.

\subsubsection{Thin film nanocomposite membranes}

Preparation of TFN membranes by IP is a concept that was first used by Jeong et al. to develop reverse osmosis membranes (Jeong, Hoek et al. 2007). It involves the integration of nanoparticles into the top PA layer by introducing them through the monomer solutions during the IP reaction. Sorribas et al. were the first to use MOFs as fillers in designing TFN membranes for SRNF (Sorribas, Gorgojo et al. 2013). Various MOFs including ZIF-8, MIL53(Al), $\mathrm{NH}_{2}-\mathrm{MIL}-53(\mathrm{Al})$ and MIL-101(Cr) with size ranging from 50-150 $\mathrm{nm}$ were dispersed in the TMC organic phase and subsequently embedded into the thin PA layer. Methanol permeability was enhanced when the porosity and pore size of the MOF increased, indicating that the pore channels in the MOFs facilitated solvent transfer. Besides that, having nanoparticles in the selective layer can effectively tune the free volume of the PA matrix. Peyravi et al. developed a TFN membrane by functionalizing $\mathrm{TiO}_{2}$ nanoparticles with either amine or chloride compounds and respectively dispersing them in an aqueous or organic phase prior to IP reaction (Peyravi, Jahanshahi et al. 2014). Aminated $\mathrm{TiO}_{2}$ nanoparticles were found to have a uniform dispersion throughout the PA layer, resulting in high methanol permeabilities of 24.0-26.0 $\mathrm{L} \mathrm{m}^{-2} \mathrm{~h}^{-1} \mathrm{bar}^{-1}$ at above $90 \%$ rejection of crystal violet $(\mathrm{CV})$ solute. The presence of $\mathrm{TiO}_{2}$ nanoparticles also lowered the chain mobility of the PA matrix, hence improving membrane stability in aggressive solvents like DMF and reducing membrane swelling.

Graphene-based nanomaterials are another emerging class of materials which is promising for SRNF owing to their two-dimensional structure as well as the chemical and thermal stability of the carbon nanomaterials (Goh, Karahan et al. 2016). In particular, GO nanosheets offer competitive advantages of easy processability in aqueous medium to obtain films with lamellar microstructures and well-defined nanopores formed by the interlayer spacing between the nanosheets. GO membranes have been reported to be stable towards acetone, ethanol, toluene and n-hexane (Huang, Li et al. 2015). As such, Shao et al. 
incorporated GO nanosheets by dispersing them into a PPy solution before inducing a polymerization reaction to form a selective layer over a PAN-H support (Shao, Cheng et al. 2014). Due to the 2-D structure of the GO nanosheets, a thinner selective layer was made possible, resulting in a significant increase in the permeabilities of methanol, ethanol and IPA without compromising on the RB rejections. To afford better selectivity, GO membranes were reduced to give reduced graphene oxide (rGO) membranes with smaller interlayer spacing (Goh, Jiang et al. 2015). Huang et al. thermally reduced GO membranes to give rGO membranes with higher selectivity towards acetone, toluene, p-xylene, naphthalene and pyrene solutes (Huang, Chen et al. 2016). Moreover, with enhanced membrane selectivity, the thickness of the rGO selective layer can be further lowered to reduce mass transfer resistance through the layer. As a result, a sub-20 nm ultrathin rGO membrane exhibited high methanol permeabilities of over $70 \mathrm{~L} \mathrm{~m}^{-2} \mathrm{~h}^{-1} \mathrm{bar}^{-1}$. Despite being ultrathin, the solvent resistance of the rGO membrane remained excellent with good stability towards acidic and basic corrosive environment.

\subsection{Hollow fiber SRNF membranes}

At present, most lab-scale studies are carried out on flat sheet membranes while commercial SRNF membranes are available as a few types of flat sheet and spiral-wound modules (Table 2). In general, the advantages of hollow fiber (HF) membrane configuration include a high area to module volume ratio, removal of the need for spacers which are necessary in spiralwound modules and the relative ease in using different hydrodynamics on the membranes (Fane, Wang et al. 2015). Due to their self-supporting structure, hollow fibers cannot withstand as high pressure as that of flat sheets, however, their operation at low pressure can reduce energy consumption. Despite these advantages, the use of SRNF HF membranes remains relatively scarce.

Several TFC HF membranes for SRNF have been reported. The membranes were prepared by IP on the lumen side of microporous polypropylene hollow fibers used as the support (Korikov, Kosaraju et al. 2006, Kosaraju and Sirkar 2008). Loh et al. fabricated ISA polyaniline HF membranes using a novel method of adding maleic acid into the dope solution before spinning in order to induce nanoporosity in the membranes (Loh, Sairam et al. 2008). The fibers crosslinked thermally were stable in acetone, methanol, THF, DMF and NMP. Kopeć et al. explored a novel method of fabricating HF membrane that involved using a bore fluid containing the crosslinker e.g. poly(ethylene imine) so that membrane formation 
was combined with crosslinking into a one-step process (Kopeć, Dutczak et al. 2011). Subsequently, Dutczak et al. explored this method to prepare P84 PI SRNF membranes and studied the process of phase inversion and chemical crosslinking during the spinning by varying the bore fluid composition (Dutczak, Tanardi et al. 2012). The hydrophilic membranes had pure ethanol permeability of $14.6-17.2 \mathrm{~L} / \mathrm{m}^{2} \cdot \mathrm{bar} \cdot \mathrm{h}$ and were partially stable in NMP.

\subsection{Summary}

Integrally skinned asymmetric and thin film composite membranes have been extensively studied for SRNF applications. In the recent years, mixed matrix membranes have shown good potential to achieve higher solvent fluxes at comparable solute rejections through the synergistic combination and reaction between the inorganic filler and polymeric material. However, the stability of these membranes remains a major barrier to their industrial implementation. At present, studies on hollow fiber membranes for SRNF applications are not as established as that for flat sheet membranes, and they are not commercially available. As a result, this thesis shall focus on the fabrication and modification of hollow fiber membranes to enhance their solvent stability and exploit the advantages of hollow fiber configuration. 
Table 2. Overview of the different types of commercial membranes for SRNF

\begin{tabular}{|c|c|c|c|c|}
\hline Manufacturer & Membrane & Materials & Configuration & Remarks \\
\hline $\begin{array}{l}\text { Koch Membrane } \\
\text { Systems }\end{array}$ & $\begin{array}{l}\text { SelRO MPS-44 \& } \\
\text { MPF-44 (250) }\end{array}$ & $\begin{array}{l}\text { Crosslinked PDMS on PAN } \\
\text { support }\end{array}$ & $\begin{array}{l}\text { Spiral-wound or } \\
\text { flat sheet }\end{array}$ & $\begin{array}{l}\text { - First company in the SRNF market } \\
\text { - MPF-50 \& MPF-60 no longer available }\end{array}$ \\
\hline SolSep BV & SolSep series (300-750) & $\begin{array}{l}\text { Believed to be TFC and } \\
\text { some with silicone top layer }\end{array}$ & Spiral-wound & - Stable in alcohols, esters, ketones \\
\hline \multirow[t]{2}{*}{ Evonik MET Ltd. } & DuraMem® ${ }^{\circledR}(150-900)$ & ISA crosslinked PI (P84®) & $\begin{array}{l}\text { Spiral-wound or } \\
\text { flat sheet }\end{array}$ & $\begin{array}{l}\text { - Stable in acetone, ethanol, IPA, } \\
\text { methanol, THF, DMF, NMP, MEK, EA } \\
\text { - Not recommended in chlorinated } \\
\text { solvents and strong amines }\end{array}$ \\
\hline & PuraMem® (280-600) & $\begin{array}{l}\text { Crosslinked PDMS on } \\
\text { crosslinked PI (P84®) }\end{array}$ & $\begin{array}{l}\text { Spiral-wound or } \\
\text { flat sheet }\end{array}$ & $\begin{array}{l}\text { Stable in apolar hydrocarbon-type } \\
\text { solvents including toluene, heptane, } \\
\text { hexane, MEK, EA } \\
\text { - Not recommended in most polar aprotic } \\
\text { solvents, chlorinated solvents and strong } \\
\text { amines }\end{array}$ \\
\hline $\begin{array}{l}\text { BORSIG Membrane } \\
\text { Technology GmbH }\end{array}$ & GMT-oNF-2 & TFC with silicone top layer & $\begin{array}{l}\text { Spiral-wound or } \\
\text { flat sheet }\end{array}$ & $\begin{array}{l}\text { - Stable in alkanes, aromatics, alcohols, } \\
\text { ethers, ketones, esters }\end{array}$ \\
\hline Inopor & Inopor (450-750) & $\begin{array}{l}\text { Ceramic membranes based } \\
\text { on } \mathrm{SiO}_{2} \text { or } \mathrm{TiO}_{2}\end{array}$ & $\begin{array}{l}\text { Mono- and } \\
\text { multichannel } \\
\text { tubes up to } 1200 \\
\mathrm{~mm}\end{array}$ & \\
\hline
\end{tabular}

* The numbers in the parentheses represent the MWCO range $\left(\mathrm{g} \mathrm{mol}^{-1}\right)$. 
CHAPTER 3 - Polyamide-imide hollow fiber membranes crosslinked with amineappended inorganic networks for SRNF under low operating pressure

\subsection{Introduction}

By separating molecules ranging in 200-1000 Da through applying a pressure gradient across a membrane, SRNF can offer many advantages compared to conventional industrial separation processes e.g. lower energy consumption and recycling of valuable solvents and reagents (Vandezande, Gevers et al. 2008). The key challenges faced in developing SRNF membranes lie in ensuring their excellent stability in organic solvents and achieving acceptable solvent permeabilities and target solute rejections over long-term operation. The majority of SRNF membranes that have been developed in the lab or commercialized are made from polymeric materials due to their lower cost, excellent processability and ease of scale-up. Significant progress has been made over the past decade to improve the stability of polymeric membranes especially in aggressive solvents like DMF and NMP, for which ISA and TFC membranes have been developed (See Toh, Lim et al. 2007, Vanherck, Vandezande et al. 2008, Loh, Sairam et al. 2009, Jimenez Solomon, Bhole et al. 2012, Sun, Chung et al. 2014).

The polymers that have been used to fabricate ISA membranes include polyimide, polysulfone, polyphenylsulfone, poly(ether ether ketone), polyaniline and polybenzimidazole. The crosslinking of polymer chains to form stable three-dimensional network structures can improve the chemical and mechanical stability of membranes. In particular, crosslinked polyimide membranes have found their application in SRNF in addition to gas separation and pervaporation (Vanherck, Koeckelberghs et al. 2013). For example, Lenzing P84 ${ }^{\circledR}$ polyimide membranes showed good chemical stability in NMP, DMF, THF and DCM after being crosslinked by aliphatic diamines (See Toh, Lim et al. 2007). Siddique et al. reported the advantages of using 3-aminopropyl trimethoxysilane (APTMS) as the crosslinking agent (Siddique, Rundquist et al. 2014). Through the hydrolysis and condensation of methoxysilane in APTMS, a rigid inorganic Si-O-Si network was obtained throughout the polyimide membrane, thus improving the mechanical properties of the membrane in addition to its chemical stability. Dutczak et al. successfully crosslinked commercial polyamide-imide (PAI) support membranes using di-isocyanates. The crosslinked membranes were resistant to NMP and showed good mechanical properties (Dutczak, Cuperus et al. 2013). 
Hollow fiber SRNF membranes are not known to be commercially available although they have the potential to make the process more efficient and attractive by operating at lower pressures and providing a higher membrane area to module volume ratio which enables the construction of more compact and simpler modules that are easy to scale-up (Dutczak, Tanardi et al. 2012). The few hollow fiber membranes that have been applied in SRNF to date were evaluated at around 5 bar (Loh, Sairam et al. 2008, Darvishmanesh, Tasselli et al. 2011). Literature has reported nanofiltration hollow fibers for water softening applications that are capable of operating at pressures as low as 2 bar, which would help to reduce energy consumption, increase productivity and lower costs (Fang, Shi et al. 2013, Fang, Shi et al. 2014, Liu, Shi et al. 2015). Low pressure operation was possible due to the fabrication of a highly porous substrate that could reduce mass transfer resistance significantly, thus allowing the resultant composite membrane to achieve high flux and rejection.

This study aims to fabricate and crosslink PAI hollow fiber membranes to make them suitable for SRNF applications. PAI is chosen due to its excellent processability, mechanical property and good chemical and thermal stability (Robertson, Guiver et al. 2004). PAI hollow fibers can be fabricated easily by non-solvent induced phase separation technique and have shown good performance in forward osmosis process after modification on a porous ultrafiltration substrate (Setiawan, Wang et al. 2011, Setiawan, Wang et al. 2012). To the best of our knowledge, this is the first study to develop PAI hollow fiber membranes for application in polar aprotic solvents under low operating pressure of 2 bar. The morphology, gel content, swelling, contact angle and mechanical strength of the modified membranes will be characterized and their performance in two common solvents, IPA and DMF, will be evaluated.

\subsection{Experimental}

\subsubsection{Materials}

Polyamide-imide (PAI) Torlon ${ }^{\circledR}$ 4000T-MV, supplied by Solvay Advanced Polymers, was used to fabricate hollow fiber substrates. N-Methyl-2-pyrrolidone (NMP, >99.5\%, CAS\#872-50-4, Merck) and lithium chloride (LiCl, anhydrous, CAS\#7447-41-8, MP Biomed) were used as the solvent and additive for preparing the dope solution respectively. Dextran with molecular weights from 6-500 kDa (CAS\#9004-54-0, Sigma) were used to characterize the molecular weight cut-off (MWCO) of the hollow fiber substrates. The 
substrates were crosslinked with (3-aminopropyl)trimethoxysilane (APTMS, 97\%, CAS\#13822-56-5, Sigma). Raffinose (594.52 Da, CAS\#17629-30-0, Merck), polyethylene glycol (PEG, 1 kDa, CAS\#25322-68-3, Merck, and 2 kDa, Sigma) were used to measure the pore size distribution of the crosslinked membranes. For nanofiltration tests, iso-propanol (IPA, $\geq 99.8 \%$, CAS\#67-63-0, Merck) and N,N-dimethylformamide (DMF, CAS\# 68-12-2, Merck) were used as the solvents and Rose Bengal (1017.64 Da, 95\%, CAS\#632-69-9, Sigma) was employed as the model solute. Milli-Q deionized water (18M $\Omega . \mathrm{cm})$ was used in all aqueous solutions. All the reagents were used as received. The chemical structures of PAI and APTMS are given in Figure 4.

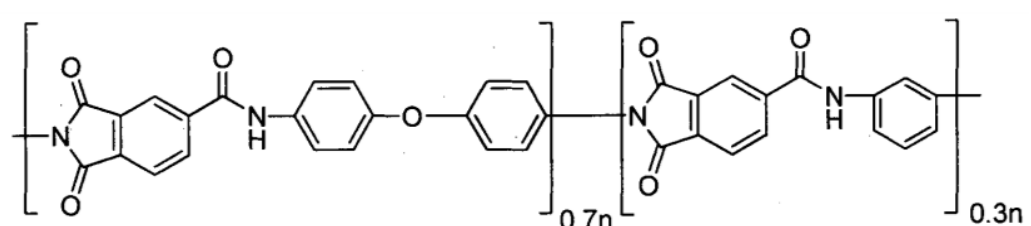

(a)<smiles>CO[Si](C)(OC)OC</smiles>

(b)

Figure 4. Chemical structure of (a) PAI and (b) APTMS

\subsubsection{Fabrication of PAI hollow fiber substrates}

Torlon ${ }^{\circledR}$ 4000T-MV was dried in a vacuum oven at $50{ }^{\circ} \mathrm{C}$ for at least 12 hours to remove moisture before preparing the dope solutions. The polymer and $\mathrm{LiCl}$ were dissolved in NMP in a jacket flask and mechanically stirred for 3-4 days at $60{ }^{\circ} \mathrm{C}$ until a homogenous dope solution was obtained. Then, the solution was cooled to room temperature and degassed under vacuum overnight before spinning. A dry-jet wet spinning technique was used to fabricate the hollow fiber substrates. The dope and bore fluid were extruded through a spinneret at controlled flow rates and went through an air gap before entering the coagulation bath (Figure 5). The hollow fibers were collected by a roller and stored in tap water for 2 days to remove residual solvent. Subsequently, they were stored in deionized water for further use. Three batches of substrates, designated \#1, \#2 and \#3, were fabricated under different spinning conditions as summarized in Table 3.

\subsubsection{Post-treatment of PAI hollow fiber substrates}

The hollow fibers were immersed in a 2\% (wt/vol) APTMS solution in a 1:1 volume mixture of IPA and deionized (DI) water at $60-80{ }^{\circ} \mathrm{C}$ for $1-5$ hours. The membranes were then 
subjected to conditioning treatment for 30 minutes in either IPA or DI water to remove the excess crosslinker and subsequently dried overnight in ambient air.

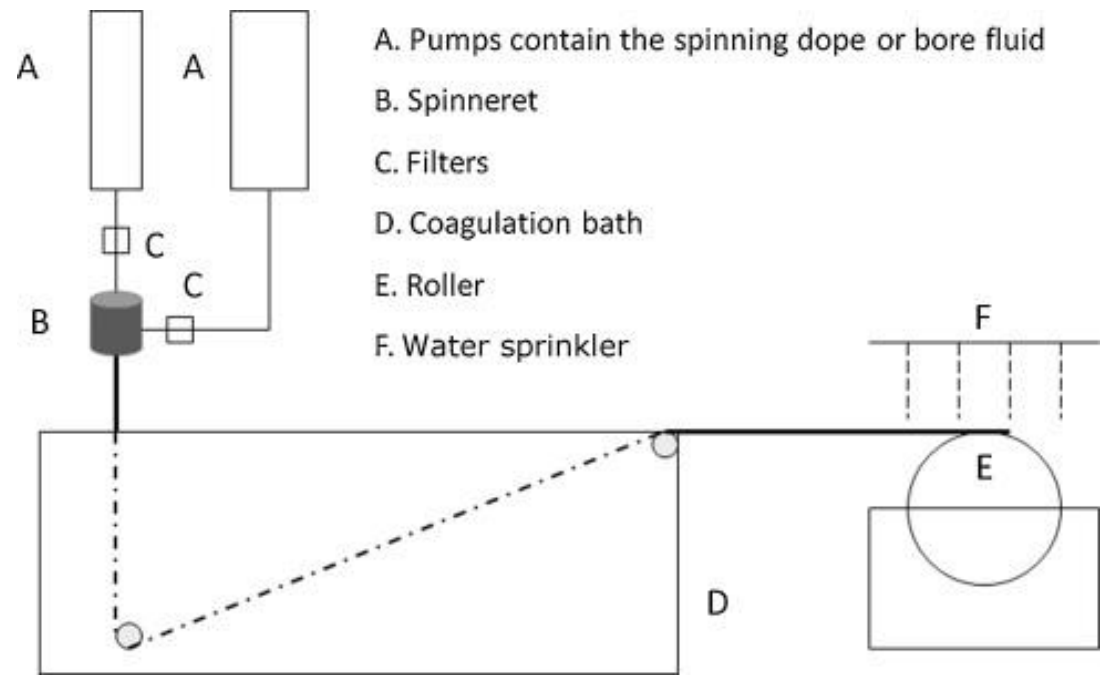

Figure 5. Typical set-up for hollow fiber spinning (Peng, Widjojo et al. 2012)

Table 3. Spinning conditions

\begin{tabular}{llll}
\hline Parameters & $\# 1$ & $\# 2$ & $\# 3$ \\
\hline $\begin{array}{l}\text { Dope composition } \\
\text { (PAI/LiCl/NMP) }(\mathrm{wt} \%)\end{array}$ & $15 / 3 / 82$ & $15 / 3 / 82$ & $14 / 3 / 83$ \\
Dope flow rate $(\mathrm{g} / \mathrm{min})$ & 6.26 & 6.26 & 6.32 \\
Bore fluid $\left(\mathrm{NMP} / \mathrm{H}_{2} \mathrm{O}\right)(\mathrm{vol} \%)$ & $25 / 75$ & $25 / 75$ & $25 / 75$ \\
Bore fluid flow rate $(\mathrm{ml} / \mathrm{min})$ & 6 & 8 & 7 \\
Air gap $(\mathrm{cm})$ & 5 & 5 & 10 \\
Take up speed $(\mathrm{m} / \mathrm{min})$ & 7 & 7 & 7 \\
External coagulant & Tap water & Tap water & Tap water \\
Spinning temperature $\left({ }^{\circ} \mathrm{C}\right)$ & 23 & 23 & 23 \\
Spinneret diameter $(\mathrm{mm})$ & 1.5 & 1.5 & 1.5 \\
ID of bore fluid needle $(\mathrm{mm})$ & 0.7 & 0.7 & 0.7 \\
\hline
\end{tabular}

\subsubsection{Characterization of membranes}

The cross-section, inner and outer surface of the hollow fiber membranes were observed using the Field Emission Scanning Electron Microscope (FESEM) JEOL JSM-7600F at an operating voltage of $5.0 \mathrm{kV}$. Prior to analysis, the membrane samples were broken in liquid nitrogen and then sputtered with a thin layer of platinum at $20 \mathrm{~mA}$ for 30 seconds using JEOL JFC-1600 Auto Fine Coater. The FESEM was equipped with an energy dispersive Xray spectrometer (EDX) for elemental mapping analysis. The functional groups on the 
surface of the membranes were analysed by a Fourier transform infrared spectrometer (FTIR, IRPrestige-21, Shimadzu) via attenuated total reflection (ATR) method.

The dynamic contact angle of the hollow fibers was measured by a tensiometer (DCAT11 Dataphysics) to determine the hydrophilicity of the membranes. For each measurement, a short fiber sample was fixed by the sample holder and experienced 5 consecutive cycles of immersion into and emersion from DI water. Based on the interaction forces, geometry of the membrane and known surface tension of the water, the advancing and receding contact angles of the membranes were calculated by the equipment software using the Wihelmy method. The stress-strain behaviour of the membranes was evaluated by tensile tests using a Zwick Roell Z0.5 universal testing machine at room temperature. The hollow fiber sample was clamped at both ends and pulled in tension at constant elongation velocity of $50 \mathrm{~mm} / \mathrm{min}$ with an initial grip to grip separation of $25 \mathrm{~mm}$. Tensile modulus, tensile stress and tensile strain at break were automatically calculated by the software.

The overall membrane porosity, $\varepsilon_{m}$, is defined as the volume of the pores over the total membrane volume and calculated by equation (1):

$$
\varepsilon_{m}=\frac{\left(m_{1}-m_{2}\right) / D_{I}}{\frac{m_{1}-m_{2}}{D_{I}}+\frac{m_{2}}{D_{P}}}
$$

where $m_{1}$ is the weight of wet membrane after soaking in IPA, $m_{2}$ is the dry weight of membrane, $D_{I}$ is the density of IPA, and $D_{P}$ is the density of polymer, which was taken to be $1.42 \mathrm{~g} / \mathrm{cm}^{3}$ for PAI.

To measure the pure water permeability (PWP) of the substrates, 4 membrane fibers were assembled in a tube and deionized water was circulated through the shell side of the hollow fibers at 1 bar for 1 hour to allow for membrane compaction and water flux to stabilize. The PWP was calculated according to the equation:

$$
J=\frac{Q}{A_{m} \times \Delta P}=\frac{Q}{n \pi D L_{e f f} \Delta P}
$$

where $J$ is the pure water permeability $\left(\mathrm{L} /\left(\mathrm{m}^{2}\right.\right.$.h.bar $\left.)\right) ; Q$ is flow rate of permeate $(\mathrm{L} / \mathrm{h}) ; A_{m}$ is membrane area $\left(\mathrm{m}^{2}\right) ; \Delta P$ is the system pressure (bar); $n$ is the number of fibers in the module; $D$ is the outer diameter of the hollow fiber $(\mathrm{m})$ and $L_{\text {eff }}$ is the effective length of the 
module (m). To measure the MWCO of the substrates, a $2000 \mathrm{ppm}$ aqueous solution containing dextran with molecular weights ranging from 6000 to 500,000 Da was filtrated from the shell side and lumen side of the hollow fibers respectively at 1 bar. A feed sample was collected at the start of filtration and permeate was collected after 30 minutes. Analysis of the dextran was performed by gel permeation chromatography (GPC) using a Polymer Laboratories-GPC 50 plus system. The MWCO was defined as the molecular weight of dextran that was retained by $90 \%$.

To measure the pore size distribution of the crosslinked membranes, $200 \mathrm{ppm}$ aqueous solutions of raffinose and PEG ( 1 and $2 \mathrm{kDa}$ ) were filtrated from the shell side of the hollow fibers at 1 bar. The concentration of each solute in the feed and permeate were analyzed using a Total Organic Carbon analyzer (TOC_VCSH, Shimadzu) and the pore size distribution was obtained by using a two-parameter log-normal distribution function (Ren, Li et al. 2006, Ren, Wang et al. 2006).

The gel content defined as the amount of material that remains undissolved in a certain solvent was measured to quantify the stability of modified membranes in DMF (Vanherck, Cano-Odena et al. 2010):

$$
\text { Gel content }(\%)=\frac{W_{f}}{W_{i}} \times 100
$$

where $W_{f}$ is the final dry weight of crosslinked membrane after 2-week immersion in DMF and $W_{i}$ is the initial dry weight of crosslinked membrane. Fibers of $10 \mathrm{~cm}$ in length were immersed in IPA or DMF and their initial and final lengths were measured. The percentage change in length of the fibers was calculated to evaluate their swelling behavior (Cheng, Zhang et al. 2014).

\subsubsection{Nanofiltration tests}

The performance of the crosslinked membranes was measured by the solvent flux and rejection of the dye, Rose Bengal (RB), in IPA and DMF, respectively. The solute concentration was fixed to $35 \mu \mathrm{M}$ which is commonly used for lab-scale SRNF experiments (Vanherck, Cano-Odena et al. 2010). The structure and properties of RB are given in Table 4. Cross-flow filtration of pure solvents was first performed from the shell side of the hollow fibers at 2 bar and room temperature to determine the pure solvent permeability after solvent 
fluxes were stabilized. Next, the membranes were filtrated with $35 \mu \mathrm{M}$ RB solution under the same conditions. After 1 hour, permeate was collected and weighed to calculate the solvent flux and permeability while the concentration of RB in the feed $\left(C_{f}\right)$ and permeate $\left(C_{p}\right)$ were measured by Shimadzu UV-1800 UV spectrophotometer at wavelength of $558 \mathrm{~nm}$. Rejection of RB was calculated using equation (4). All measurements were carried out with at least three samples and the average values were reported.

$$
\text { Rejection }(\%)=\left(1-\frac{C_{p}}{C_{f}}\right) \times 100
$$

Table 4. Properties of Rose Bengal

\begin{tabular}{|c|c|c|c|c|}
\hline Solute & $\begin{array}{l}\text { Molecular } \\
\text { weight (Da) }\end{array}$ & Structure & Charge & $\begin{array}{l}\text { Molar volume } \\
\left(\mathrm{cm}^{3} / \mathrm{mol}\right)\end{array}$ \\
\hline $\begin{array}{l}\text { Rose } \\
\text { Bengal } \\
\text { (RB) }\end{array}$ & 1017 & & -2 & 273 \\
\hline
\end{tabular}

\subsection{Results and discussion}

\subsubsection{Characterization of PAI hollow fiber substrates}

The properties of the hollow fiber substrates are summarized in Table 5. They have similar wall thickness and PWP, but differ in their outer and inner skin MWCO values. The analysis on MWCOs of membranes revealed that \#2 and \#3 have a denser outer skin than that for \#1. The inner and outer skins of \#1 seem to be equally dense, while \#3 showed the highest difference in MWCOs of inner and outer skins. Comparing \#1 and \#2, the higher bore fluid flow rate resulted in faster diffusion of bore fluid through the membrane such that the polymer concentration at the outer surface was reduced at a faster rate. This could explain why \#2 has a lower outer skin MWCO than \#1.

The cross-section and outer surface morphologies of the substrates are shown in Figure 6. All of them have finger-like structures developed from the inner and outer surfaces of the 
membranes with a thin sponge-like structure in the middle. The outer surfaces of the membranes are observed to be smooth with no large pores or defects. The substrates prepared in this work possess a uniform structure with a narrow pore size distribution which could facilitate more uniform crosslinking of the membranes.

Table 5. Properties of PAI hollow fiber substrates

\begin{tabular}{llll}
\hline Properties & $\# 1$ & $\# 2$ & $\# 3$ \\
\hline Fiber ID/OD $(\mathrm{mm} / \mathrm{mm})$ & $0.928 / 1.212$ & $1.030 / 1.307$ & $0.968 / 1.256$ \\
Fiber wall thickness $(\mu \mathrm{m})$ & $142 \pm 4$ & $139 \pm 6$ & $144 \pm 5$ \\
PWP (L/m 2 .h.bar) & $139 \pm 4$ & $122 \pm 10$ & $133 \pm 4$ \\
Outer skin MWCO (kDa) & $24 \pm 8$ & $13 \pm 2$ & $14 \pm 3$ \\
Inner skin MWCO (kDa) & $22 \pm 4$ & $19 \pm 3$ & $27 \pm 6$ \\
Porosity $(\%)$ & $75 \pm 0.7$ & $76 \pm 1.9$ & $80 \pm 0.8$ \\
\hline
\end{tabular}
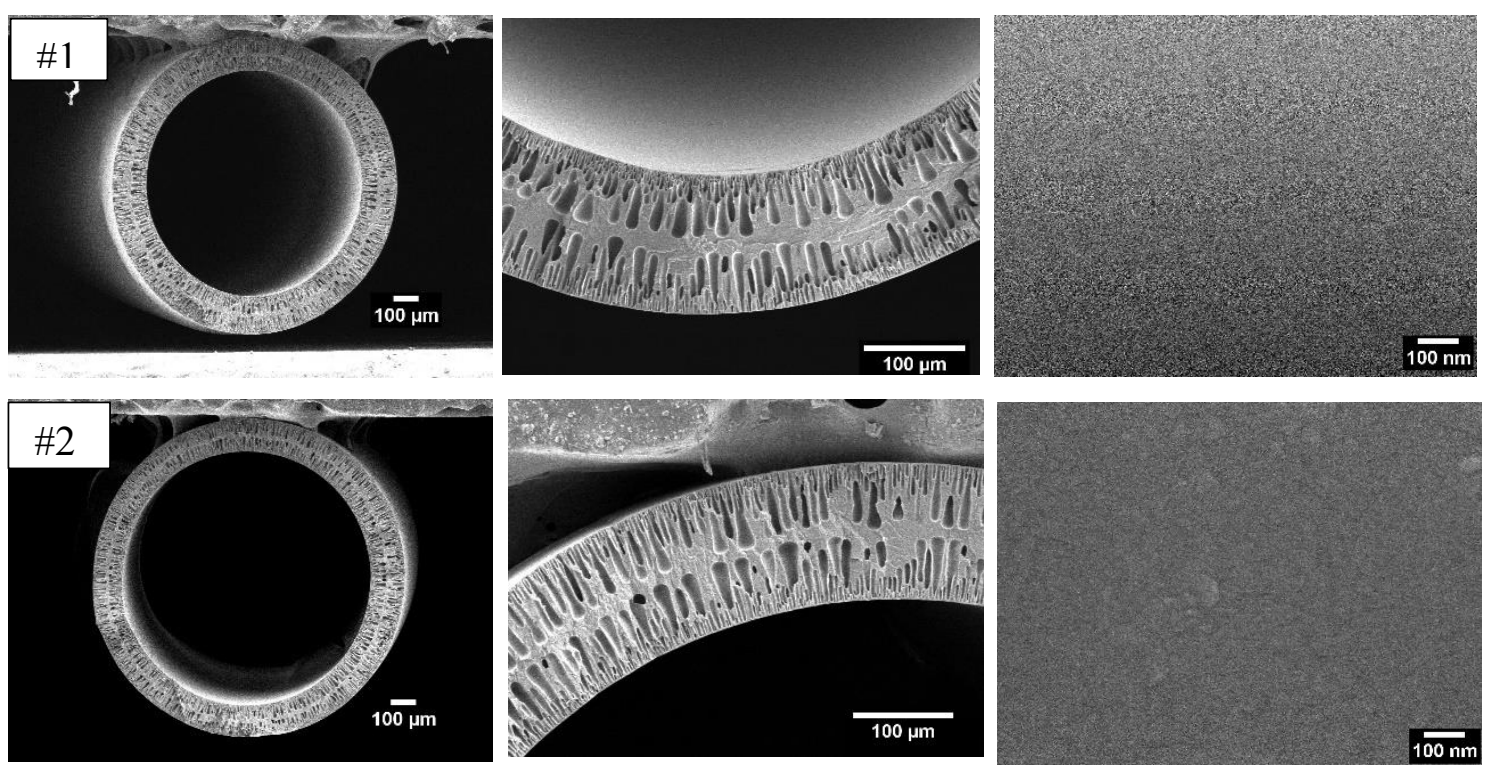

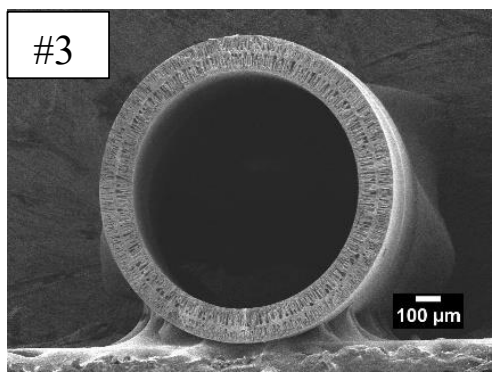

(a)

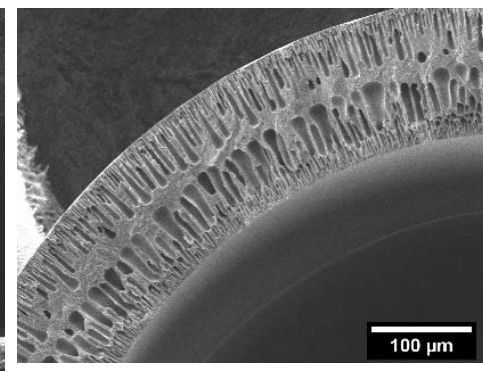

(b)

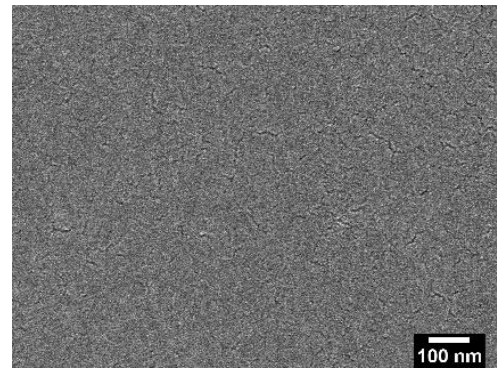

(c)

Figure 6. SEM images of hollow fiber substrates: (a) and (b) cross-sections;

(c) outer surfaces 


\subsubsection{Optimization of crosslinking conditions}

To improve the stability in aggressive solvents, the hollow fiber substrates were crosslinked with APTMS that could form inorganic network structures inside of the substrates. APTMS possesses organic amine groups that could participate in a ring-opening reaction with imide groups present in PAI, as well as inorganic silicon ( $\mathrm{Si}$ ) groups that could hydrolyze and condense to form a polysiloxane ( $\mathrm{Si}-\mathrm{O}-\mathrm{Si}$ ) network (Siddique, Rundquist et al. 2014). An illustration of the proposed crosslinking reaction is shown in Figure 7.

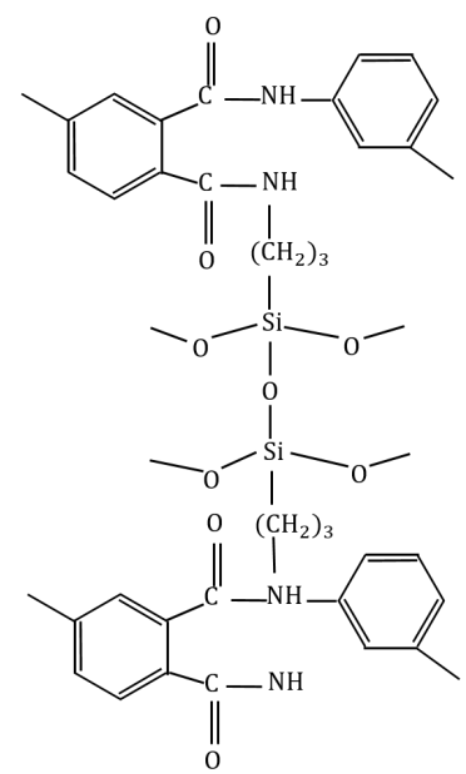

Figure 7. Reaction mechanism between PAI and APTMS

An excess amount of APTMS was introduced with a concentration fixed at $2 \%$. To determine the optimal crosslinking temperature and time, substrate \#1 was treated with APTMS at varying temperatures of 60 to $80{ }^{\circ} \mathrm{C}$ for 1 hour and conditioned with DI water. The mechanical properties of the resultant membranes are shown in Table 6 . The rigidity of the membranes increased as indicated in the increase in tensile modulus. However, the crosslinking at high temperature such as $80{ }^{\circ} \mathrm{C}$ made the membranes too brittle to be used in nanofiltration processes. Thus, subsequent modification was chosen to be carried out at $60{ }^{\circ} \mathrm{C}$. 
Table 6. Effect of crosslinking temperature on mechanical properties of membrane

\begin{tabular}{llll}
\hline $\begin{array}{l}\text { Crosslinking } \\
\text { temperature }\left({ }^{\circ} \mathrm{C}\right)\end{array}$ & $\begin{array}{l}\text { Tensile modulus } \\
(\mathrm{MPa})\end{array}$ & $\begin{array}{l}\text { Stress at break } \\
(\mathrm{MPa})\end{array}$ & $\begin{array}{l}\text { Strain at break } \\
(\%)\end{array}$ \\
\hline Original \#1 & $207 \pm 18$ & $10.5 \pm 0.2$ & $33.6 \pm 4.2$ \\
60 & $225 \pm 20$ & $12.0 \pm 0.5$ & $23.1 \pm 2.7$ \\
70 & $244 \pm 25$ & $12.1 \pm 0.2$ & $17.7 \pm 0.7$ \\
80 & $262 \pm 6$ & $9.7 \pm 0.2$ & $6.1 \pm 0.9$ \\
\hline
\end{tabular}

The effects on gel content, contact angle and mechanical properties of \#1 membranes crosslinked at $60{ }^{\circ} \mathrm{C}$ for 1 to 5 hours are summarized in Table 7 . Gel content of the original substrate could not be measured due to its dissolution in DMF. A high gel content of over 90\% was obtained for all membranes. With increasing reaction time, the gel content increased to over $98 \%$ for crosslinking time of 3 hours and beyond. The contact angle of the membranes decreased with increasing treatment time, indicating that membranes became more hydrophilic. This could be due to the presence of more silanol $(\mathrm{Si}-\mathrm{OH})$ groups on the membrane surface as more APTMS reacted with the polymer. As the membranes crosslinked for 5 hours became too brittle and there was no significant increase in gel content, the optimal reaction time was chosen to be 3 hours.

Table 7. Effect of crosslinking time on membrane properties

\begin{tabular}{llllll}
\hline $\begin{array}{l}\text { Crosslinking } \\
\text { time (hr) }\end{array}$ & $\begin{array}{l}\text { Gel content } \\
(\%)\end{array}$ & $\begin{array}{l}\text { Contact Angle } \\
\left({ }^{\circ}\right)\end{array}$ & $\begin{array}{l}\text { Tensile modulus } \\
(\mathrm{MPa})\end{array}$ & $\begin{array}{l}\text { Stress at break } \\
(\mathrm{MPa})\end{array}$ & $\begin{array}{l}\text { Strain at } \\
\text { break }(\%)\end{array}$ \\
\hline Original \#1 & $\begin{array}{l}\text { Dissolved in } \\
\text { DMF }\end{array}$ & $82.7 \pm 1.8$ & $207 \pm 18$ & $10.5 \pm 0.2$ & $33.6 \pm 4.2$ \\
1 & $>90$ & $78.5 \pm 0.7$ & $225 \pm 20$ & $12.0 \pm 0.5$ & $23.1 \pm 2.7$ \\
2 & $>90$ & $65.8 \pm 2.0$ & $272 \pm 20$ & $11.6 \pm 0.5$ & $17.1 \pm 1.8$ \\
3 & $>98$ & $64.8 \pm 3.2$ & $290 \pm 23$ & $10.9 \pm 0.8$ & $15.8 \pm 2.2$ \\
5 & $>98$ & $62.1 \pm 3.0$ & $281 \pm 22$ & $10.3 \pm 0.5$ & $7.5 \pm 1.6$ \\
\hline
\end{tabular}

In subsequent experiments, the three substrates were crosslinked with $2 \%$ APTMS at $60{ }^{\circ} \mathrm{C}$ for 3 hours. For each substrate, one batch of membranes was conditioned with IPA (denoted as \#x-I, $\mathrm{x}$ is the substrate number) while another batch was conditioned with DI water (denoted as \#x-H) after immersing in the APTMS solution. The gel contents of all the crosslinked membranes were similar regardless of the conditioning solution, while marginal differences were observed in the contact angle and mechanical properties of \#x-I membranes 
compared to that of \#x-H membranes. Hence, it appears that the different conditioning solutions did not affect the gel content, hydrophilicity or mechanical properties of the membranes significantly.

\subsubsection{Characterization of crosslinked hollow fiber membranes}

The FTIR spectrum of \#1 membranes before and after crosslinking with $2 \%$ APTMS at $60{ }^{\circ} \mathrm{C}$ for 3 hours is shown in Figure 8. The spectra of \#1-H and \#1-I membranes were similar. Characteristic imide peaks were observed for the original substrate at 1778, 1691 and 1375 $\mathrm{cm}^{-1}$. After crosslinking, the imide peaks disappeared while the intensity of amide peaks at 1641 and $1535 \mathrm{~cm}^{-1}$ became stronger. These peaks agree with a previous report (Zhang, Wang et al. 2011) and confirm that the PAI substrate was successfully crosslinked by APTMS. A stronger peak observed at $1089 \mathrm{~cm}^{-1}$ could be attributed to the Si-O-Si bond (Xie, Dao et al. 2011) which forms the inorganic network within the membrane.

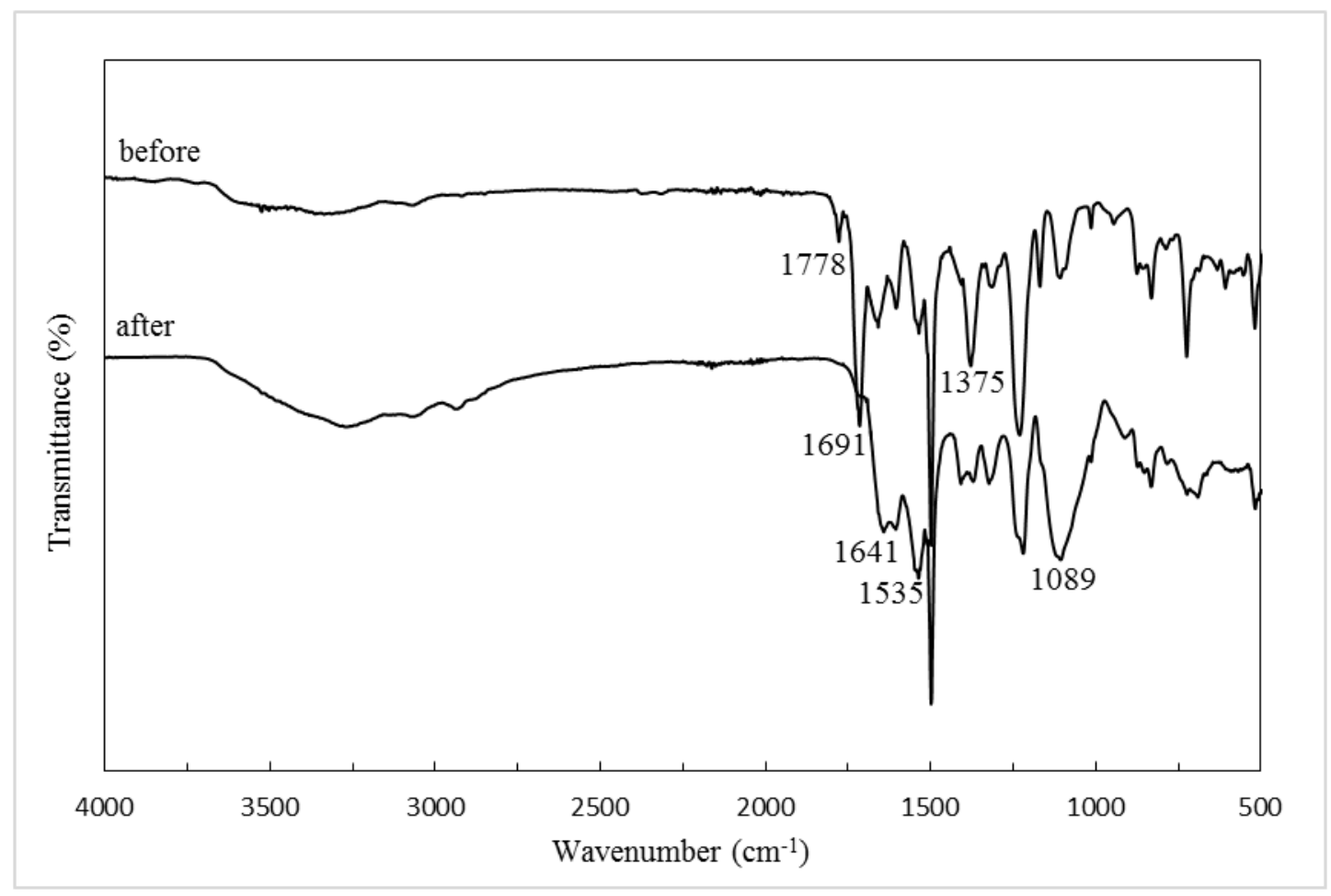

Figure 8. FTIR spectra of \#1 membranes before and after crosslinking with 2\% APTMS at $60{ }^{\circ} \mathrm{C}$ for 3 hours

EDX was used to analyze the cross-section of the crosslinked membranes and a representative map showing the distribution of $\mathrm{Si}$ for \#1-H membrane is shown in Figure 9. A uniform distribution of silica throughout the entire membrane cross-section can be 
observed and this indicates that the silica inorganic network was successfully formed in the whole membrane.

The cross-section and outer surface morphologies of \#2 membranes are shown in Figure 10. In Figure 10a, finger-like structures can still be seen in the crosslinked membranes but their sizes are reduced. It is likely that crosslinking decreased the porosity of the membranes by closing or blocking some of the membrane pores. As shown in Figure 10b, the outer skin layer was observed to be thicker in the crosslinked membranes with an estimated average thickness of $1.5 \mu \mathrm{m}$ compared to that of pristine membrane $(0.7 \mu \mathrm{m})$. From visual observation of Figure 10c, the outer surfaces of the crosslinked membranes appeared rougher than those for pristine membrane as small spherical particles were observed to be embedded in the membranes as well as on the surface, where their density is generally higher in $\# \mathrm{x}-\mathrm{H}$ membranes compared to \#x-I ones. These particles are most likely silica particles formed by the condensation of APTMS. A possible reason for the higher number of silica particles found in $\# \mathrm{x}-\mathrm{H}$ membranes could be the condensation residual APTMS facilitated by the DI water. Meanwhile, conditioning with IPA might allow the unreacted APTMS to be removed from the membrane easier and faster.

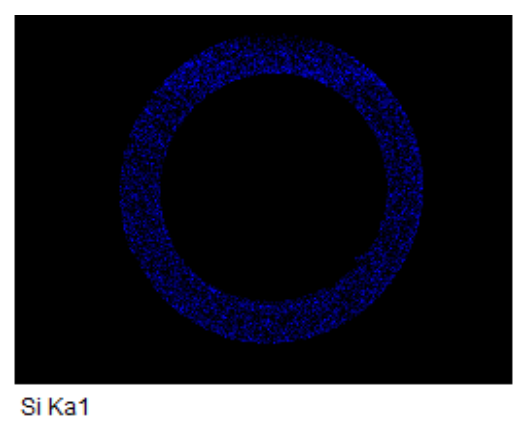

Figure 9. Elemental map showing the distribution of Si on the cross-section of crosslinked membrane (\#1-H)

To investigate the swelling properties of membranes, the length of each hollow fiber sample was measured before and after the immersion in solvents. The untreated substrates showed a $5 \%$ increase in length after immersion in IPA for 5 hours and no more change was observed after that. In contrast, the crosslinked hollow fibers showed improved swelling resistance such that the length of fibers increased only 1-2\% after immersion in IPA. However, increased swelling was observed when the crosslinked fibers were immersed in DMF as they experienced a $4-5 \%$ increase in length. Overall results indicate that some swelling effects 
were still present in crosslinked membranes although the degree of swelling was reduced compared to that of untreated hollow fiber. Note that the swelling property of the PAI membranes in this work is comparable with that of PPSU hollow fibers fabricated by Darvishmanesh et al. (Darvishmanesh, Tasselli et al. 2011).
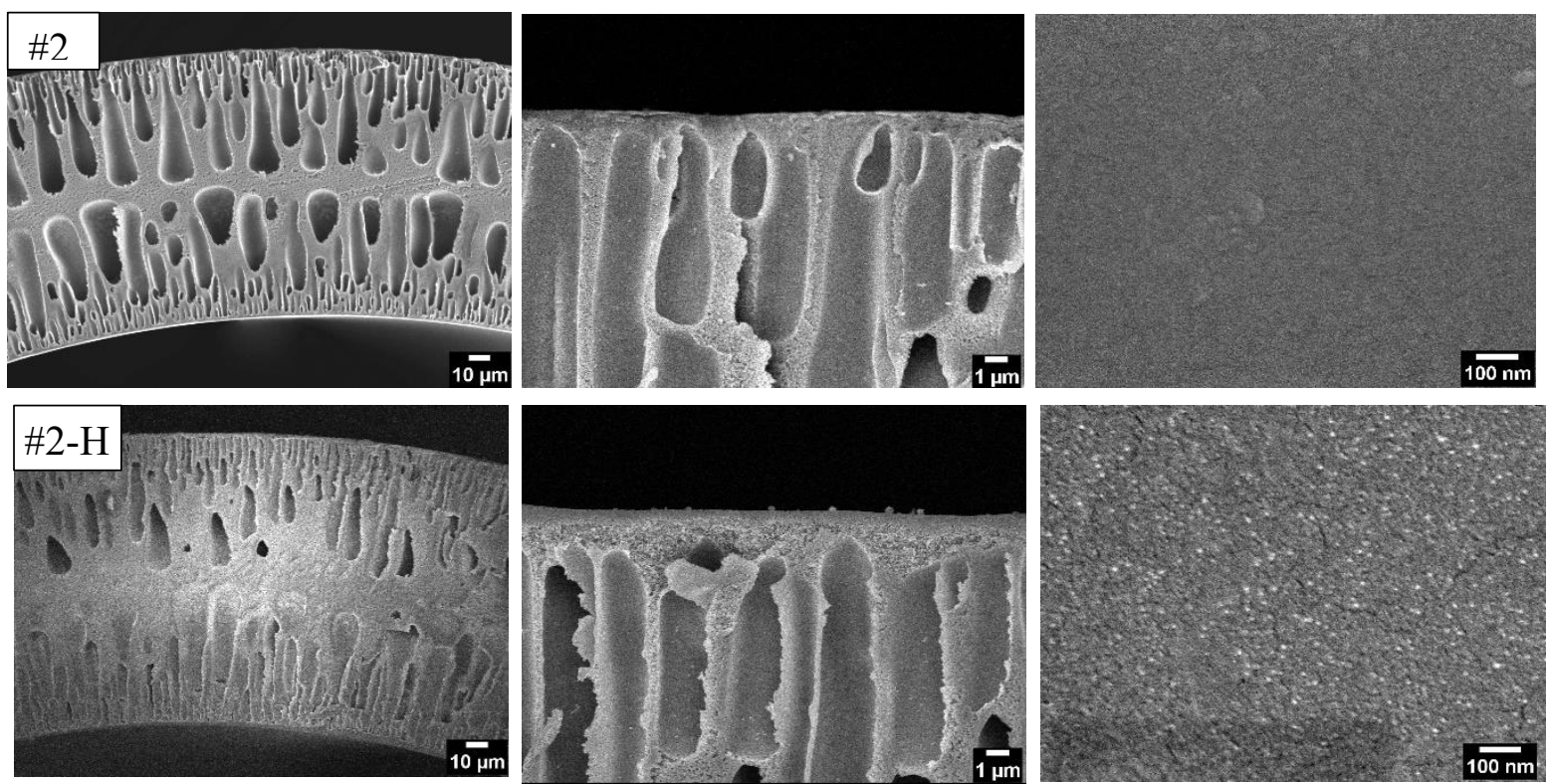

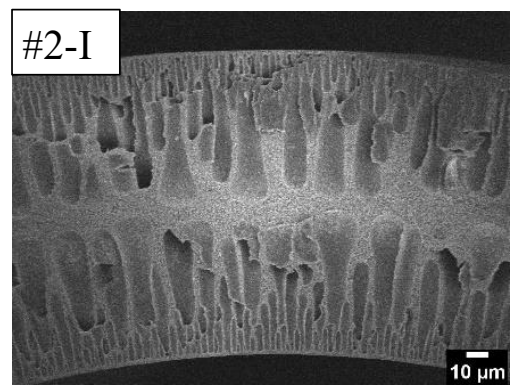

(a)

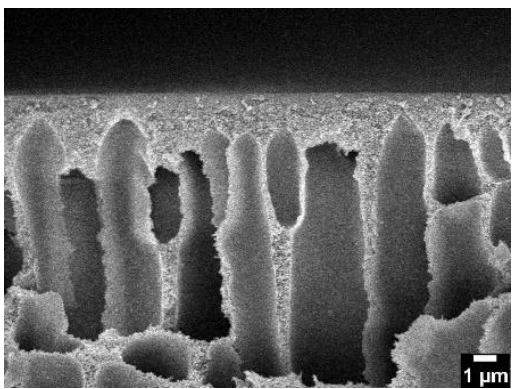

(b)

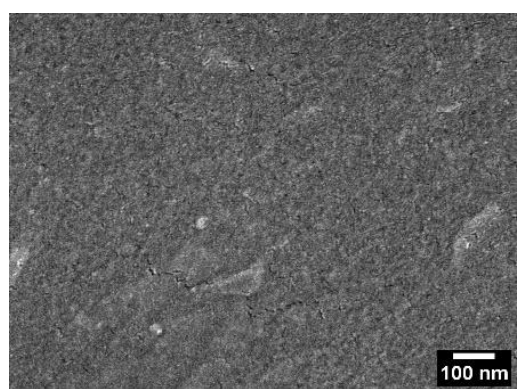

(c)

Figure 10. SEM images of \#2 membranes before and after the crosslinking: (a) Crosssection; (b) cross-section of outer skin area; (c) the surface of outer skin

\subsubsection{Nanofiltration performance}

The solvent filtration performance of the membranes was conducted under a relatively low pressure of 2 bar and is presented in Figure 11 and 12. The highly porous hollow fiber substrate with a very thin wall (see Table 5) made it possible by reducing mass transfer resistance. All membranes prepared in this work showed higher solvent flux for IPA than that for DMF as observed in previous work (Li, De Feyter et al. 2008, Li, Vandezande et al. 2008, Ahmadiannamini, Li et al. 2012, Chen 2013). Although the different conditioning solutions caused minor changes in the membrane properties such as their gel content, contact 
angle, mechanical properties and degree of swelling, a significant difference was observed in the solvent fluxes and RB rejections between \#x-I and \#x-H membranes. \#x-I membranes consistently showed higher solvent fluxes and thus higher solvent permeabilities coupled with lower RB rejections ranging 75-87\%. On the other hand, \#x-H membranes had lower permeabilities and high $\mathrm{RB}$ rejections of $96-99 \%$.

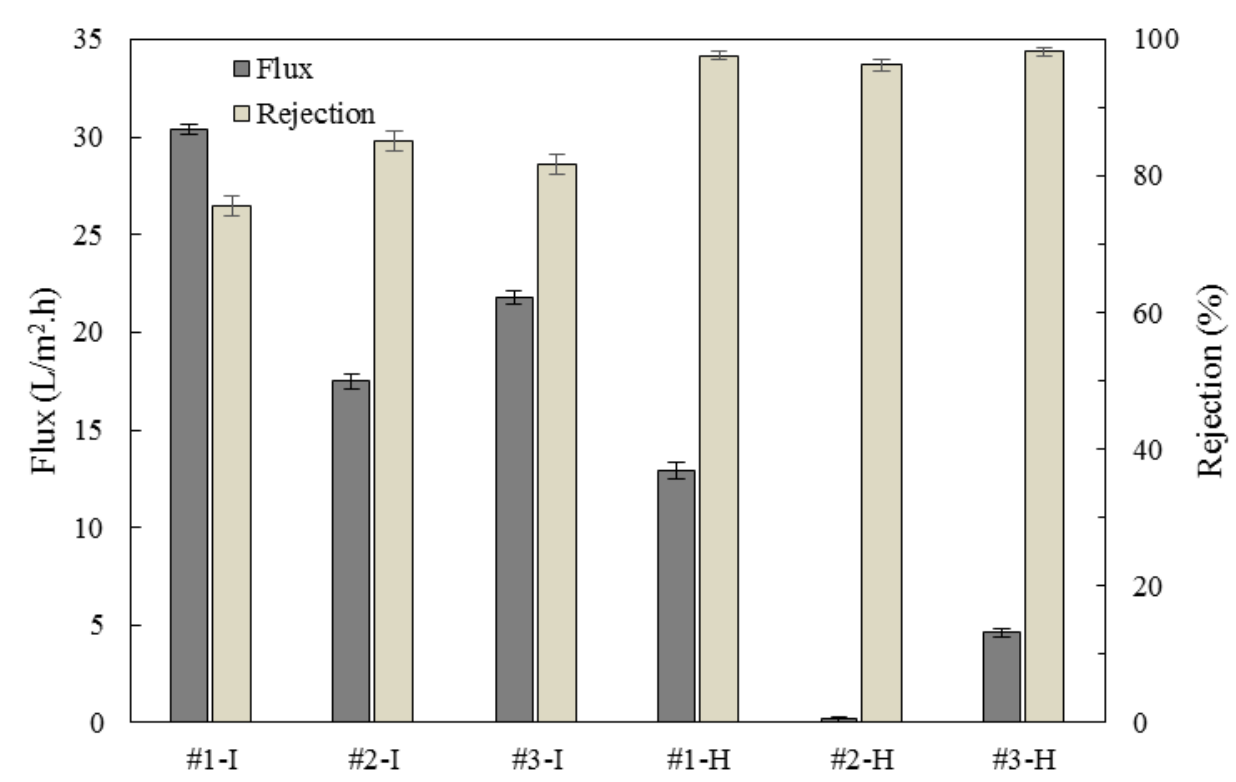

Figure 11. IPA flux and RB rejection of membranes (operating conditions: 2 bar, room temperature)

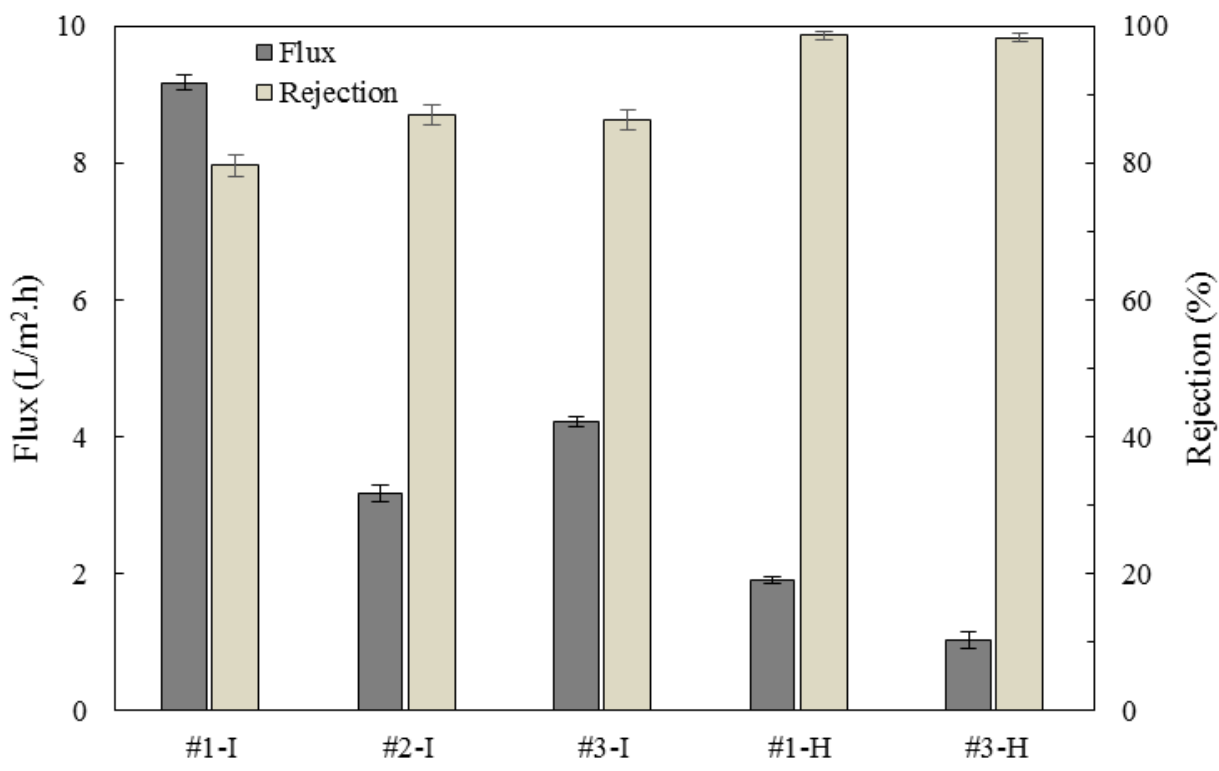

Figure 12. DMF flux and RB rejection of membranes (operating conditions: 2 bar, room temperature); no flux was obtained for \#2-H 
This difference is most likely caused by the changes in membrane morphology as described in Section 3.3.3. The high density of silica particles in membrane may be a major reason why \#x-H membranes had lower fluxes than \#x-I membranes as they may lead to pore blockage. This can explain the difference in pore size distribution of the membranes as shown in Figure 13. The membranes conditioned with $\mathrm{H}_{2} \mathrm{O}$ had lower mean pore diameters and narrower pore size distributions, which can explain their lower permeability and higher rejection values compared to membranes conditioned with IPA. Out of the membranes conditioned with $\mathrm{H}_{2} \mathrm{O}$, \#1-H had a larger mean pore size and slightly broader pore size distribution than \#2-H and \#3-H, which could be attributed to \#1 substrate having the least dense skin layer. Thus it showed the largest solvent flux while rejection was not compromised. This is likely because its pore size and relatively narrow pore size distribution remained tight enough to reject RB molecules. \#2-H and \#3-H, having substrates with similarly dense skin layer, had similar pore size distribution and mean pore size. However, as \#3 had a more porous inner skin which suggests less mass transfer resistance, the solvent flux of \#3-H was higher than that of \#2-H although rejections were similar. \#2-H became so dense such that the IPA flux was very low and no DMF flux could be obtained. On the other hand, when membranes were conditioned with IPA, less silica particles were found on the membrane surface, reducing the extent of pore blockage. As a result, the membranes showed higher mean pore diameters and broader pore size distributions, which led to higher solvent fluxes but lower rejections.

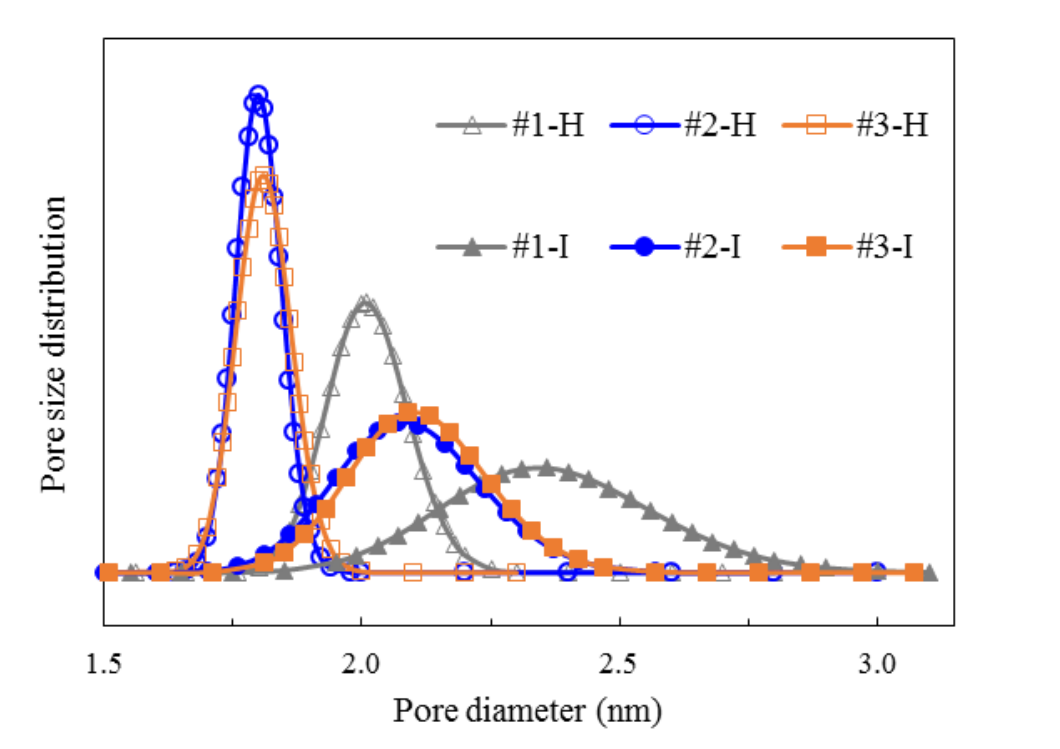

Figure 13. Pore size distribution of membranes 
\#1-H membrane was chosen to be subjected to extended filtration tests to investigate their long-term stability and the results are presented in Figure 14. Over the 7-day testing period in IPA, the membranes showed a slight decrease in flux and showed IPA permeability of 6.4 $\mathrm{L} /\left(\mathrm{m}^{2}\right.$.h.bar) with RB rejections above $97 \%$. Testing of the membranes in DMF was limited to a 3-day period due to the instability of the epoxy used to seal the module. DMF permeability was relatively stable at $0.9 \mathrm{~L} /\left(\mathrm{m}^{2}\right.$. h.bar) while rejections of over $98 \%$ were achieved.

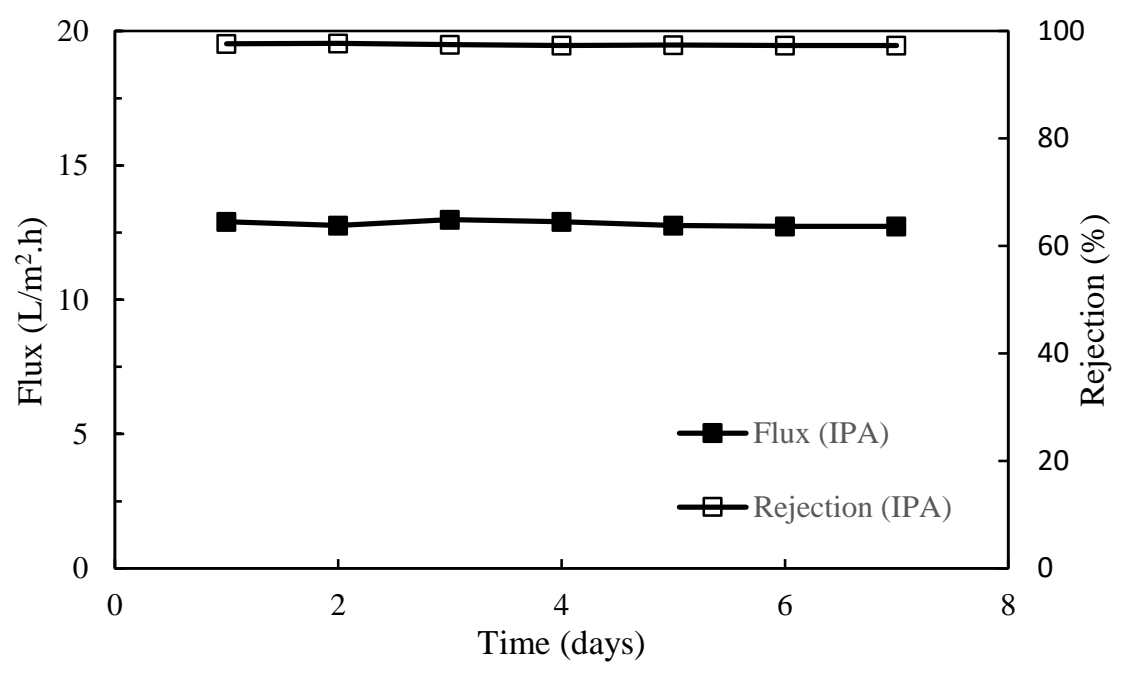

(a)

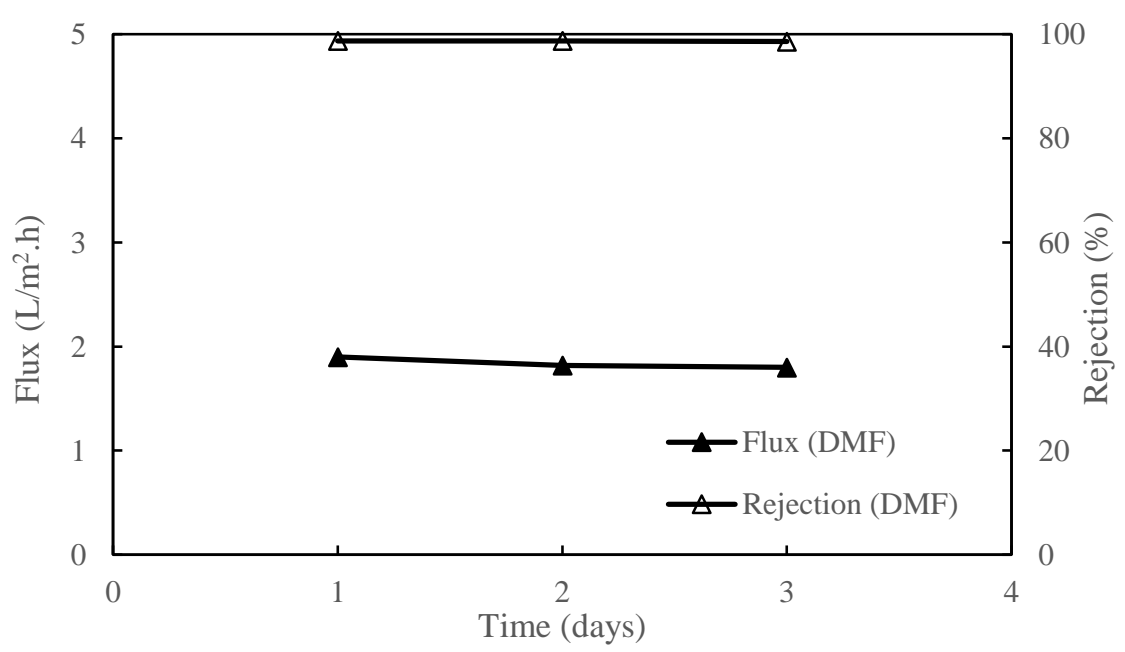

(b)

Figure 14. Long-term separation performance of \#1-H membrane in (a) IPA (b) DMF (feed solution: $35 \mu \mathrm{M}$ RB in IPA or DMF; operating conditions: 2 bar, room temperature)

The performances of various ISA SRNF membranes that were tested in RB solutions are listed in Table 8. \#1-H membrane showed a much higher IPA permeability compared to the 
PPSU hollow fiber reported previously, although the RB rejection decreased slightly. The DMF permeability of the membrane also falls within the typical range, and it should be noted that the PAI HF membranes in this work were tested at a relatively low pressure of 2 bar compared to that in previous studies.

Table 8. Comparison of various SRNF membranes

\begin{tabular}{|c|c|c|c|c|c|c|c|}
\hline \multirow[b]{2}{*}{$\begin{array}{l}\text { Membrane } \\
\text { material }\end{array}$} & \multirow[b]{2}{*}{$\begin{array}{l}\text { Membrane } \\
\text { type }\end{array}$} & \multirow[b]{2}{*}{$\begin{array}{l}\text { Operating } \\
\text { conditions }\end{array}$} & \multicolumn{2}{|c|}{ RB/IPA } & \multicolumn{2}{|c|}{ RB/DMF } & \multirow[b]{2}{*}{ Ref. } \\
\hline & & & $\begin{array}{l}\text { Permeability } \\
\left(\mathrm{L} / \mathrm{m}^{2} \cdot \mathrm{h} \cdot \mathrm{bar}\right)\end{array}$ & $\begin{array}{l}\text { Rejection } \\
(\%)\end{array}$ & $\begin{array}{l}\text { Permeability } \\
\left(\mathrm{L} / \mathrm{m}^{2} \cdot \mathrm{h} . \text { bar }\right)\end{array}$ & $\begin{array}{l}\text { Rejection } \\
(\%)\end{array}$ & \\
\hline Crosslinked PAI & ISA HF & $\begin{array}{l}2 \text { bar } \\
\text { Shell } \\
\text { filtration }\end{array}$ & 6.4 & 97.3 & 0.9 & 98.6 & Present work \\
\hline PPSU & ISA HF & $\begin{array}{l}5 \text { bar } \\
\text { Lumen } \\
\text { filtration }\end{array}$ & $0.02^{\mathrm{a}}$ & 98.6 & - & - & $\begin{array}{l}\text { (Darvishmanesh, } \\
\text { Jansen et al. } \\
\text { 2011) }\end{array}$ \\
\hline DuraMem® 150 & Commercial & $10 \mathrm{bar}$ & - & - & 0.36 & 98 & (Pérez- \\
\hline DuraMem® 200 & & & & & 0.95 & 99 & $\begin{array}{l}\text { Manríquez, } \\
\text { Aburabi'e et al. } \\
\text { 2015) }\end{array}$ \\
\hline UV cured PI & ISA & - & 1.4 & 96 & - & - & $\begin{array}{l}\text { (Hendrix, } \\
\text { Vanherck et al. } \\
\text { 2012) }\end{array}$ \\
\hline $\begin{array}{l}\text { Crosslinked } \\
\text { Matrimid PI }\end{array}$ & ISA & 6 bar & - & - & $2.6-5.4$ & $95-99$ & $\begin{array}{l}\text { (Vanherck, } \\
\text { Vandezande et } \\
\text { al. 2008) }\end{array}$ \\
\hline $\begin{array}{l}\text { Crosslinked P84 } \\
\text { PI }\end{array}$ & ISA & 10 bar & - & - & 0.43 & 99 & $\begin{array}{l}\text { (Hermans, Dom } \\
\text { et al. 2015) }\end{array}$ \\
\hline PSf/SPEEK & ISA & 15 bar & 0.47 & 96 & - & - & $\begin{array}{l}\text { (Struzynska- } \\
\text { Piron, Loccufier } \\
\text { et al. 2013) }\end{array}$ \\
\hline PSf & ISA & 5-15 bar & 1.2 & 94 & - & - & $\begin{array}{l}\text { (Li, De Feyter et } \\
\text { al. 2008) }\end{array}$ \\
\hline PEEKWC & ISA & 11 bar & 0.9 & 99.8 & - & - & $\begin{array}{l}\text { (da Silva Burgal, } \\
\text { Peeva et al. } \\
2015 \text { ) }\end{array}$ \\
\hline TВPEEK & ISA & 10 bar & 1 & 90 & - & - & $\begin{array}{l}\text { (Buonomenna, } \\
\text { Golemme et al. } \\
2011 \text { ) }\end{array}$ \\
\hline
\end{tabular}

\subsection{Conclusions}

PAI hollow fiber substrates were fabricated by non-solvent induced phase inversion method and crosslinked with APTMS to form amine-tethered inorganic networks in the membranes. The optimization of crosslinking conditions led to a good stability of the membrane in 
organic solvents, including polar aprotic solvents like DMF, together with improved mechanical property and hydrophilicity.

A 30-minute conditioning with either IPA or DI water after the crosslinking reaction affected the morphology and thus the nanofiltration performance of the membranes. Higher solvent permeabilities and moderate RB rejections of $75-87 \%$ were observed for membranes conditioned with IPA after crosslinking, while lower permeabilities and high rejections of 96-99\% were obtained from membranes conditioned with DI water. The membranes were tested for a 7-day period and showed a stable performance under low operating pressure of 2 bar, achieving a permeability of $6.4 \mathrm{~L} /\left(\mathrm{m}^{2} . h\right.$.bar $)$ in IPA and $0.9 \mathrm{~L} /\left(\mathrm{m}^{2} . h . b a r\right)$ in DMF with rejections over $97 \%$ and $98 \%$ respectively. With further development, they show potential to be used in SRNF processes and make them more efficient and economically viable. 


\section{CHAPTER 4 - CONCLUSION \& RECOMMENDATIONS}

\subsection{Conclusions}

SRNF membranes offer a promising new generation of filtration membranes that can potentially be applied in a wide range of industrial processes in the petrochemical, food, fine chemical and pharmaceutical industries. So far, hollow fiber SRNF membranes are not commercially available although the hollow fiber configuration can provide several advantages over spiral-wound modules as described in Section 2.3. In light of this, this thesis focuses on the development of hollow fiber membranes intended for SRNF application, with the objective to achieve good long-term stability in aggressive solvents and improve solvent permeabilities and solute rejections under low operating pressure.

In this study, polyamide-imide hollow membranes were fabricated and post-treated with an organic-inorganic crosslinker and conditioning solution. The resultant membranes were characterized to understand the reaction mechanism and the effect of crosslinking and conditioning on the morphology and performance of the membranes. Extended filtration tests were carried out to evaluate the long-term stability of the membranes. The following conclusions can be drawn:

Highly porous asymmetric polyamide-imide hollow fiber substrates were fabricated by non-solvent induced phase inversion method. The substrates possess a narrow pore size distribution which could facilitate more uniform crosslinking of the membranes.

Crosslinking of the PAI substrates with 3-aminopropyl trimethoxysilane formed an inorganic polysiloxane ( $\mathrm{Si}-\mathrm{O}-\mathrm{Si}$ ) network in the membranes, improving their mechanical properties and stability in polar aprotic solvents such as DMF. A high gel content of over $98 \%$ after immersion of the membranes in DMF was obtained under the optimal crosslinking condition. The membranes also became more hydrophilic due to the presence of $\mathrm{Si}-\mathrm{OH}$ groups on the membrane surface.

The membranes were subjected to a 30-minute conditioning with either isopropanol or deionized water after treatment with APTMS solution. This affected the morphology of the membranes and thus their nanofiltration performance. A higher 
density of spherical silica particles were embedded in the membranes treated with deionized water, which is attributed to the condensation of APTMS facilitated by deionized water.

Membranes conditioned with DI water had lower mean pore diameters and narrower pore size distributions, thus they showed lower solvent permeabilities and higher rejection of RB compared to membranes conditioned with IPA.

The best-performing membrane showed a stable performance under continuous operation for 7 days, achieving a permeability of $6.4 \mathrm{~L} /\left(\mathrm{m}^{2}\right.$.h.bar) in IPA and 0.9 $\mathrm{L} /\left(\mathrm{m}^{2}\right.$.h.bar) in DMF with $\mathrm{RB}$ rejections of over $97 \%$ and $98 \%$, respectively, under 2 bar operating pressure.

\subsection{Recommendations}

The successful industrial implementation of SRNF processes would require the whole membrane system to be extremely stable in harsh conditions including polar aprotic solvents as well as acidic and basic environments. Hence, newly developed membranes should be tested for their stability in extreme $\mathrm{pH}$ conditions as well. More attention can be devoted to improve the stability of SRNF membranes in acids and bases. As polyimides have been reported to have limited stability in strong acids and bases, novel membrane modification methods await to be explored. The use of alternative polymeric materials such as PBI could be feasible, however factors such as ease of processability into hollow fibers and cost have to be considered as well (Valtcheva, Kumbharkar et al. 2014).

In this study, a one-step treatment with a crosslinker was sufficient to make the porous membrane substrates in the nanofiltration range. However, it is generally more difficult to control the thickness of the separation layer in integrally skinned asymmetric membranes. Hence, the post-treatment method developed in this study could be used to prepare the solvent-stable support layer for thin film composite membranes. However, such a support layer has to remain highly porous and mechanically stable after crosslinking. A highviscosity polymer, e.g. Torlon 4000T-HV, or polyetherimide could be explored for membrane fabrication. Spinning parameters would also need to be adjusted to obtain substrates with higher MWCO. 


\section{REFERENCES}

Aerts, S., A. Vanhulsel, A. Buekenhoudt, H. Weyten, S. Kuypers, H. Chen, M. Bryjak, L. E. M. Gevers, I. F. J. Vankelecom and P. A. Jacobs (2006). "Plasma-treated PDMS-membranes in solvent resistant nanofiltration: Characterization and study of transport mechanism." Journal of Membrane Science 275(1-2): 212-219.

Aerts, S., H. Weyten, A. Buekenhoudt, L. E. M. Gevers, I. F. J. Vankelecom and P. A. Jacobs (2004). "Recycling of the homogeneous Co-Jacobsen catalyst through solvent-resistent nanofiltration (SRNF)." Chemical Communications(6): 710-711.

Ahmadiannamini, P., X. Li, W. Goyens, N. Joseph, B. Meesschaert and I. F. J. Vankelecom (2012). "Multilayered polyelectrolyte complex based solvent resistant nanofiltration membranes prepared from weak polyacids." Journal of Membrane Science 394-395(0): 98106.

Ahmadiannamini, P., X. Li, W. Goyens, B. Meesschaert, W. Vanderlinden, S. De Feyter and I. F. J. Vankelecom (2012). "Influence of polyanion type and cationic counter ion on the SRNF performance of polyelectrolyte membranes." Journal of Membrane Science 403404(0): 216-226.

Basu, S., M. Maes, A. Cano-Odena, L. Alaerts, D. E. De Vos and I. F. J. Vankelecom (2009). "Solvent resistant nanofiltration (SRNF) membranes based on metal-organic frameworks." Journal of Membrane Science 344(1-2): 190-198.

Bhanushali, D., S. Kloos and D. Bhattacharyya (2002). "Solute transport in solvent-resistant nanofiltration membranes for non-aqueous systems: experimental results and the role of solute-solvent coupling." Journal of Membrane Science 208(1-2): 343-359.

Bhanushali, D., S. Kloos, C. Kurth and D. Bhattacharyya (2001). "Performance of solventresistant membranes for non-aqueous systems: solvent permeation results and modeling." Journal of Membrane Science 189(1): 1-21. 
Budd, P. M., B. S. Ghanem, S. Makhseed, N. B. McKeown, K. J. Msayib and C. E. Tattershall (2004). "Polymers of intrinsic microporosity (PIMs): robust, solutionprocessable, organic nanoporous materials." Chem. Commun.(2): 230-231.

Buekenhoudt, A., F. Bisignano, G. De Luca, P. Vandezande, M. Wouters and K. Verhulst (2013). "Unravelling the solvent flux behaviour of ceramic nanofiltration and ultrafiltration membranes." J. Membr. Sci. 439: 36-47.

Buonomenna, M. G., G. Golemme, J. C. Jansen and S. H. Choi (2011). "Asymmetric PEEKWC membranes for treatment of organic solvent solutions." Journal of Membrane Science 368(1-2): 144-149.

Chen, D. (2013). "Solvent-resistant nanofiltration membranes based on multilayered polyelectrolytes deposited on silicon composite." Journal of Applied Polymer Science 129(6): 3156-3161.

Cheng, X. Q., Y. L. Zhang, Z. X. Wang, Z. H. Guo, Y. P. Bai and L. Shao (2014). "Recent Advances in Polymeric Solvent-Resistant Nanofiltration Membranes." Advances in Polymer Technology: n/a-n/a.

da Silva Burgal, J., L. G. Peeva, S. Kumbharkar and A. Livingston (2015). "Organic solvent resistant poly(ether-ether-ketone) nanofiltration membranes." Journal of Membrane Science 479(0): 105-116.

Darvishmanesh, S., A. Buekenhoudt, J. Degrève and B. Van der Bruggen (2009). "Coupled series-parallel resistance model for transport of solvent through inorganic nanofiltration membranes." Separation and Purification Technology 70(1): 46-52.

Darvishmanesh, S., A. Buekenhoudt, J. Degrève and B. Van der Bruggen (2009). "General model for prediction of solvent permeation through organic and inorganic solvent resistant nanofiltration membranes." Journal of Membrane Science 334(1-2): 43-49.

Darvishmanesh, S., J. Degrève and B. V. d. Bruggen (2010). "Performance of SolventPretreated Polyimide Nanofiltration Membranes for Separation of Dissolved Dyes from Toluene." Industrial \& Engineering Chemistry Research 49(19): 9330-9338. 
Darvishmanesh, S., J. Degreve and B. Van der Bruggen (2010). "Mechanisms of solute rejection in solvent resistant nanofiltration: the effect of solvent on solute rejection." Physical Chemistry Chemical Physics 12(40): 13333-13342.

Darvishmanesh, S., J. Degreve and B. Van der Bruggen (2010). "Physicochemical characterization of transport in nanosized membrane structures." Chemphyschem 11(2): 404-411.

Darvishmanesh, S., J. Degrève and B. Van der Bruggen (2009). "Comparison of pressure driven transport of ethanol/n-hexane mixtures through dense and microporous membranes." Chemical Engineering Science 64(17): 3914-3927.

Darvishmanesh, S., L. Firoozpour, J. Vanneste, P. Luis, J. Degreve and B. V. d. Bruggen (2011). "Performance of solvent resistant nanofiltration membranes for purification of residual solvent in the pharmaceutical industry: experiments and simulation." Green Chemistry 13(12): 3476-3483.

Darvishmanesh, S., J. C. Jansen, F. Tasselli, E. Tocci, P. Luis, J. Degrève, E. Drioli and B. Van der Bruggen (2011). "Novel polyphenylsulfone membrane for potential use in solvent nanofiltration." Journal of Membrane Science 379(1-2): 60-68.

Darvishmanesh, S., F. Tasselli, J. C. Jansen, E. Tocci, F. Bazzarelli, P. Bernardo, P. Luis, J. Degrève, E. Drioli and B. Van der Bruggen (2011). "Preparation of solvent stable polyphenylsulfone hollow fiber nanofiltration membranes." Journal of Membrane Science 384(1-2): 89-96.

Dobrak-Van Berlo, A., I. F. J. Vankelecom and B. Van der Bruggen (2011). "Parameters determining transport mechanisms through unfilled and silicalite filled PDMS-based membranes and dense PI membranes in solvent resistant nanofiltration: Comparison with pervaporation." Journal of Membrane Science 374(1-2): 138-149. 
Dobrak, A., B. Verrecht, H. Van den Dungen, A. Buekenhoudt, I. F. J. Vankelecom and B. Van der Bruggen (2010). "Solvent flux behavior and rejection characteristics of hydrophilic and hydrophobic mesoporous and microporous $\mathrm{TiO}_{2}$ and $\mathrm{ZrO}_{2}$ membranes." J. Membr. Sci. 346(2): 344-352.

Dong, H., X. Y. Qu, L. Zhang, L. H. Cheng, H. L. Chen and C. J. Gao (2011). "Preparation and characterization of surface-modified zeolite-polyamide thin film nanocomposite membranes for desalination." Desalin. Water Treat. 34(1-3): 6-12.

Dutczak, S. M., F. P. Cuperus, M. Wessling and D. F. Stamatialis (2013). "New crosslinking method of polyamide-imide membranes for potential application in harsh polar aprotic solvents." Separation and Purification Technology 102(0): 142-146.

Dutczak, S. M., C. R. Tanardi, K. K. Kopeć, M. Wessling and D. Stamatialis (2012). "“Chemistry in a spinneret" to fabricate hollow fibers for organic solvent filtration." Separation and Purification Technology 86(0): 183-189.

Fane, A. G., R. Wang and M. X. Hu (2015). "Synthetic membranes for water purification: status and future." Angew. Chem. Int. Ed. 54(11): 3368-3386.

Fang, W., L. Shi and R. Wang (2013). "Interfacially polymerized composite nanofiltration hollow fiber membranes for low-pressure water softening." Journal of Membrane Science 430: $129-139$.

Fang, W., L. Shi and R. Wang (2014). "Mixed polyamide-based composite nanofiltration hollow fiber membranes with improved low-pressure water softening capability." Journal of Membrane Science 468: 52-61.

Florian, E., M. Modesti and M. Ulbricht (2007). "Preparation and characterization of novel solvent-resistant nanofiltration composite membranes based on crosslinked polyurethanes." Ind. Eng. Chem. Res. 46(14): 4891-4899.

Fontananova, E., G. Di Profio, F. Artusa and E. Drioli (2013). "Polymeric homogeneous composite membranes for separations in organic solvents." J. Appl. Polym. Sci. 129(4): 1653-1659. 
Fritsch, D., P. Merten, K. Heinrich, M. Lazar and M. Priske (2012). "High performance organic solvent nanofiltration membranes: Development and thorough testing of thin film composite membranes made of polymers of intrinsic microporosity (PIMs)." J. Membr. Sci. 401(0): 222-231.

Geens, J., K. Peeters, B. Van der Bruggen and C. Vandecasteele (2005). "Polymeric nanofiltration of binary water-alcohol mixtures: Influence of feed composition and membrane properties on permeability and rejection." Journal of Membrane Science $\mathbf{2 5 5}$ (12): $255-264$.

Geens, J., B. Van der Bruggen and C. Vandecasteele (2004). "Characterisation of the solvent stability of polymeric nanofiltration membranes by measurement of contact angles and swelling." Chemical Engineering Science 59(5): 1161-1164.

Geens, J., B. Van der Bruggen and C. Vandecasteele (2006). "Transport model for solvent permeation through nanofiltration membranes." Separation and Purification Technology 48(3): 255-263.

Gevers, L. E. M., S. Aldea, I. F. J. Vankelecom and P. A. Jacobs (2006). "Optimisation of a lab-scale method for preparation of composite membranes with a filled dense top-layer." Journal of Membrane Science 281(1-2): 741-746.

Gevers, L. E. M., I. F. J. Vankelecom and P. A. Jacobs (2005). "Zeolite filled polydimethylsiloxane (PDMS) as an improved membrane for solvent-resistant nanofiltration (SRNF)." Chemical Communications(19): 2500-2502.

Gevers, L. E. M., I. F. J. Vankelecom and P. A. Jacobs (2006). "Solvent-resistant nanofiltration with filled polydimethylsiloxane (PDMS) membranes." Journal of Membrane Science 278(1-2): 199-204.

Goh, K., W. C. Jiang, H. E. Karahan, S. L. Zhai, L. Wei, D. S. Yu, A. G. Fane, R. Wang and Y. Chen (2015). "All-Carbon Nanoarchitectures as High-Performance Separation Membranes with Superior Stability." Adv. Funct. Mater. 25(47): 7348-7359. 
Goh, K., H. E. Karahan, L. Wei, T. H. Bae, A. G. Fane, R. Wang and Y. Chen (2016). "Carbon nanomaterials for advancing separation membranes: A strategic perspective." Carbon 109: 694-710.

Gorgojo, P., S. Karan, H. C. Wong, M. F. Jimenez-Solomon, J. T. Cabral and A. G. Livingston (2014). "Ultrathin Polymer Films with Intrinsic Microporosity: Anomalous Solvent Permeation and High Flux Membranes." Adv. Funct. Mater. 24(30): 4729-4737.

Guizard, C., A. Ayral and A. Julbe (2002). "Potentiality of organic solvents filtration with ceramic membranes. A comparison with polymer membranes." Desalination 147(1-3): 275280.

Hendrix, K., K. Vanherck and I. F. J. Vankelecom (2012). "Optimization of solvent resistant nanofiltration membranes prepared by the in-situ diamine crosslinking method." Journal of Membrane Science 421-422(0): 15-24.

Hermans, S., E. Dom, H. Mariën, G. Koeckelberghs and I. F. J. Vankelecom (2015). "Efficient synthesis of interfacially polymerized membranes for solvent resistant nanofiltration." Journal of Membrane Science 476(0): 356-363.

Huang, L., J. Chen, T. Gao, M. Zhang, Y. Li, L. Dai, L. Qu and G. Shi (2016). "Reduced Graphene Oxide Membranes for Ultrafast Organic Solvent Nanofiltration." Advanced Materials 28(39): 8669-8674.

Huang, L., Y. Li, Q. Zhou, W. Yuan and G. Shi (2015). "Graphene oxide membranes with tunable semipermeability in organic solvents." Adv. Mater. 27(25): 3797-3802.

Jansen, J. C., S. Darvishmanesh, F. Tasselli, F. Bazzarelli, P. Bernardo, E. Tocci, K. Friess, A. Randova, E. Drioli and B. Van der Bruggen (2013). "Influence of the blend composition on the properties and separation performance of novel solvent resistant polyphenylsulfone/polyimide nanofiltration membranes." Journal of Membrane Science 447(0): 107-118. 
Jeong, B. H., E. M. V. Hoek, Y. S. Yan, A. Subramani, X. F. Huang, G. Hurwitz, A. K. Ghosh and A. Jawor (2007). "Interfacial polymerization of thin film nanocomposites: A new concept for reverse osmosis membranes." J. Membr. Sci. 294(1-2): 1-7.

Jimenez-Solomon, M. F., Q. Song, K. E. Jelfs, M. Munoz-Ibanez and A. G. Livingston (2016). "Polymer nanofilms with enhanced microporosity by interfacial polymerization." Nat. Mater. 15(7): 760-767.

Jimenez Solomon, M. F., Y. Bhole and A. G. Livingston (2012). "High flux membranes for organic solvent nanofiltration (OSN) - Interfacial polymerization with solvent activation." Journal of Membrane Science 423-424(0): 371-382.

Jimenez Solomon, M. F., Y. Bhole and A. G. Livingston (2013). "High flux hydrophobic membranes for organic solvent nanofiltration (OSN) - Interfacial polymerization, surface modification and solvent activation." Journal of Membrane Science 434(0): 193-203.

Karan, S., Z. Jiang and A. G. Livingston (2015). "Sub-10 nm polyamide nanofilms with ultrafast solvent transport for molecular separation." Science 348(6241): 1347-1351.

Kariduraganavar, M. Y., J. G. Varghese, S. K. Choudhari and R. H. Olley (2009). "Organic-Inorganic Hybrid Membranes: Solving the Trade-off Phenomenon Between Permeation Flux and Selectivity in Pervaporation." Ind. Eng. Chem. Res. 48(8): 4002-4013.

Kim, J. and B. Van der Bruggen (2010). "The use of nanoparticles in polymeric and ceramic membrane structures: review of manufacturing procedures and performance improvement for water treatment." Environ. Pollut. 158(7): 2335-2349.

Kim, J. K., S. Y. Yang, Y. Lee and Y. Kim (2010). "Functional nanomaterials based on block copolymer self-assembly." Prog. Polym. Sci. 35(11): 1325-1349.

Koh, D. Y., B. A. McCool, H. W. Deckman and R. P. Lively (2016). "Reverse osmosis molecular differentiation of organic liquids using carbon molecular sieve membranes." Science 353(6301): 804-807. 
Kopeć, K. K., S. M. Dutczak, M. Wessling and D. F. Stamatialis (2011). "Chemistry in a spinneret-On the interplay of crosslinking and phase inversion during spinning of novel hollow fiber membranes." Journal of Membrane Science 369(1-2): 308-318.

Korikov, A. P., P. B. Kosaraju and K. K. Sirkar (2006). "Interfacially polymerized hydrophilic microporous thin film composite membranes on porous polypropylene hollow fibers and flat films." Journal of Membrane Science 279(1-2): 588-600.

Kosaraju, P. B. and K. K. Sirkar (2008). "Interfacially polymerized thin film composite membranes on microporous polypropylene supports for solvent-resistant nanofiltration." Journal of Membrane Science 321(2): 155-161.

Li, X., S. De Feyter, D. Chen, S. Aldea, P. Vandezande, F. Du Prez and I. F. J. Vankelecom (2008). "Solvent-Resistant Nanofiltration Membranes Based on Multilayered Polyelectrolyte Complexes." Chemistry of Materials 20(12): 3876-3883.

Li, X., S. De Feyter and I. F. J. Vankelecom (2008). "Poly(sulfone)/sulfonated poly(ether ether ketone) blend membranes: Morphology study and application in the filtration of alcohol based feeds." Journal of Membrane Science 324(1-2): 67-75.

Li, X., P. Vandezande and I. F. J. Vankelecom (2008). "Polypyrrole modified solvent resistant nanofiltration membranes." Journal of Membrane Science 320(1-2): 143-150.

Li, X. F., C. A. Fustin, N. Lefevre, J. F. Gohy, S. De Feyter, J. De Baerdemaeker, W. Egger and I. F. J. Vankelecom (2010). "Ordered nanoporous membranes based on diblock copolymers with high chemical stability and tunable separation properties." J. Mater. Chem. 20(21): 4333-4339.

Li, X. F., W. Goyens, P. Ahmadiannamini, W. Vanderlinden, S. De Feyter and I. Vankelecom (2010). "Morphology and performance of solvent-resistant nanofiltration membranes based on multilayered polyelectrolytes: Study of preparation conditions." J. Membr. Sci. 358(1-2): 150-157. 
Liu, C., S. Kulprathipanja, A. M. W. Hillock, S. Husain and W. J. Koros (2008). Recent Progress in Mixed-Matrix Membranes. Advanced Membrane Technology and Applications, John Wiley \& Sons, Inc.: 787-819.

Liu, C., L. Shi and R. Wang (2015). "Crosslinked layer-by-layer polyelectrolyte nanofiltration hollow fiber membrane for low-pressure water softening with the presence of SO42- in feed water." Journal of Membrane Science 486: 169-176.

Liu, Y., R. Wang and T. S. Chung (2001). "Chemical cross-linking modification of polyimide membranes for gas separation." Journal of Membrane Science 189(2): 231-239.

Livingston, A., L. Peeva, S. Han, D. Nair, S. S. Luthra, L. S. White and L. M. Freitas Dos Santos (2003). "Membrane Separation in Green Chemical Processing." Annals of the New York Academy of Sciences 984(1): 123-141.

Loh, X. X., M. Sairam, A. Bismarck, J. H. G. Steinke, A. G. Livingston and K. Li (2009). "Crosslinked integrally skinned asymmetric polyaniline membranes for use in organic solvents." Journal of Membrane Science 326(2): 635-642.

Loh, X. X., M. Sairam, J. H. G. Steinke, A. G. Livingston, A. Bismarck and K. Li (2008). "Polyaniline hollow fibres for organic solvent nanofiltration." $\underline{\text { Chemical }}$ Communications(47): 6324-6326.

Luthra, S. S., X. Yang, L. M. Freitas dos Santos, L. S. White and A. G. Livingston (2002). "Homogeneous phase transfer catalyst recovery and re-use using solvent resistant membranes." Journal of Membrane Science 201(1-2): 65-75.

Machado, D. o. R., D. Hasson and R. Semiat (1999). "Effect of solvent properties on permeate flow through nanofiltration membranes. Part I: investigation of parameters affecting solvent flux." Journal of Membrane Science 163(1): 93-102.

Machado, D. o. R., D. Hasson and R. Semiat (2000). "Effect of solvent properties on permeate flow through nanofiltration membranes: Part II. Transport model." Journal of Membrane Science 166(1): 63-69. 
Mahajan, R. and W. J. Koros (2000). "Factors controlling successful formation of mixedmatrix gas separation materials." Ind. Eng. Chem. Res. 39(8): 2692-2696.

McKeown, N. B. (2012). "Polymers of Intrinsic Microporosity." ISRN Materials Science 2012: $1-16$.

Moore, T. T. and W. J. Koros (2005). "Non-ideal effects in organic-inorganic materials for gas separation membranes." J. Mol. Struct. 739(1-3): 87-98.

Mulder, M. (2006). Basic principles of membrane technology, Dordrecht ; Boston : Kluwer Academic, c1996.

Namvar-Mahboub, M. and M. Pakizeh (2013). "Development of a novel thin film composite membrane by interfacial polymerization on polyetherimide/modified $\mathrm{SiO}_{2}$ support for organic solvent nanofiltration." Sep. Purif. Technol. 119(0): 35-45.

Peeva, L. G., M. Sairam and A. G. Livingston (2010). 2.05 - Nanofiltration Operations in Nonaqueous Systems. Comprehensive Membrane Science and Engineering. E. Drioli and L. Giorno. Oxford, Elsevier: 91-113.

Peng, N., N. Widjojo, P. Sukitpaneenit, M. M. Teoh, G. G. Lipscomb, T.-S. Chung and J.Y. Lai (2012). "Evolution of polymeric hollow fibers as sustainable technologies: Past, present, and future." Progress in Polymer Science 37(10): 1401-1424.

Pérez-Manríquez, L., J. Aburabi'e, P. Neelakanda and K.-V. Peinemann (2015). "Crosslinked PAN-based thin-film composite membranes for non-aqueous nanofiltration."

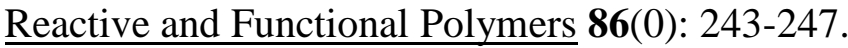

Peyravi, M., M. Jahanshahi, A. Rahimpour, A. Javadi and S. Hajavi (2014). "Novel thin film nanocomposite membranes incorporated with functionalized $\mathrm{TiO}_{2}$ nanoparticles for organic solvent nanofiltration." Chem. Eng. J. 241(0): 155-166.

Ren, J., Z. Li and F.-S. Wong (2006). "A new method for the prediction of pore size distribution and MWCO of ultrafiltration membranes." Journal of Membrane Science 279(1-2): 558-569. 
Ren, J., R. Wang, H.-Y. Zhang, Z. Li, D. T. Liang and J. H. Tay (2006). "Effect of PVDF dope rheology on the structure of hollow fiber membranes used for $\mathrm{CO} 2$ capture." Journal of Membrane Science 281(1-2): 334-344.

Robertson, G. P., M. D. Guiver, M. Yoshikawa and S. Brownstein (2004). "Structural determination of Torlon ${ }^{\circledR}$ 4000T polyamide-imide by NMR spectroscopy." Polymer 45(4): 1111-1117.

Rowsell, J. L. C. and O. M. Yaghi (2004). "Metal-organic frameworks: A new class of porous materials." Microporous and Mesoporous Materials 73(1-2): 3-14.

Rundquist, E. M., C. J. Pink and A. G. Livingston (2012). "Organic solvent nanofiltration: a potential alternative to distillation for solvent recovery from crystallisation mother liquors." Green Chemistry 14(8): 2197-2205.

Sairam, M., X. X. Loh, Y. Bhole, I. Sereewatthanawut, K. Li, A. Bismarck, J. H. G. Steinke and A. G. Livingston (2010). "Spiral-wound polyaniline membrane modules for organic solvent nanofiltration (OSN)." Journal of Membrane Science 349(1-2): 123-129.

Sairam, M., X. X. Loh, K. Li, A. Bismarck, J. H. G. Steinke and A. G. Livingston (2009). "Nanoporous asymmetric polyaniline films for filtration of organic solvents." Journal of Membrane Science 330(1-2): 166-174.

Scarpello, J. T., D. Nair, L. M. Freitas dos Santos, L. S. White and A. G. Livingston (2002). "The separation of homogeneous organometallic catalysts using solvent resistant nanofiltration." Journal of Membrane Science 203(1-2): 71-85.

Schäfer, A. I., A. G. Fane and T. D. Waite (2005). Nanofiltration: principles and applications, Elsevier Advanced Technology.

See-Toh, Y. H., M. Silva and A. Livingston (2008). "Controlling molecular weight cut-off curves for highly solvent stable organic solvent nanofiltration (OSN) membranes." J. Membr. Sci. 324(1-2): 220-232. 
See Toh, Y. H., F. W. Lim and A. G. Livingston (2007). "Polymeric membranes for nanofiltration in polar aprotic solvents." Journal of Membrane Science 301(1-2): 3-10.

Sereewatthanawut, I., F. W. Lim, Y. S. Bhole, D. Ormerod, A. Horvath, A. T. Boam and A. G. Livingston (2010). "Demonstration of Molecular Purification in Polar Aprotic Solvents by Organic Solvent Nanofiltration." Organic Process Research \& Development 14(3): 600611.

Setiawan, L., R. Wang, K. Li and A. G. Fane (2011). "Fabrication of novel poly(amideimide) forward osmosis hollow fiber membranes with a positively charged nanofiltrationlike selective layer." Journal of Membrane Science 369(1-2): 196-205.

Setiawan, L., R. Wang, K. Li and A. G. Fane (2012). "Fabrication and characterization of forward osmosis hollow fiber membranes with antifouling NF-like selective layer." Journal of Membrane Science 394-395: 80-88.

Shao, L., X. Q. Cheng, Z. X. Wang, J. Ma and Z. H. Guo (2014). "Tuning the performance of polypyrrole-based solvent-resistant composite nanofiltration membranes by optimizing polymerization conditions and incorporating graphene oxide." J. Membr. Sci. 452(0): 82-89.

Sheth, J. P., Y. Qin, K. K. Sirkar and B. C. Baltzis (2003). "Nanofiltration-based diafiltration process for solvent exchange in pharmaceutical manufacturing." Journal of Membrane Science 211(2): 251-261.

Siddique, H., E. Rundquist, Y. Bhole, L. G. Peeva and A. G. Livingston (2014). "Mixed matrix membranes for organic solvent nanofiltration." Journal of Membrane Science 452(0): 354-366.

Silva, P., L. G. Peeva and A. G. Livingston (2008). Nanofiltration in Organic Solvents. Advanced Membrane Technology and Applications, John Wiley \& Sons, Inc.: 451-467.

Soroko, I. and A. Livingston (2009). "Impact of TiO2 nanoparticles on morphology and performance of crosslinked polyimide organic solvent nanofiltration (OSN) membranes." $\underline{\mathrm{J}}$. Membr. Sci. 343(1-2): 189-198. 
Soroko, I., M. P. Lopes and A. Livingston (2011). "The effect of membrane formation parameters on performance of polyimide membranes for organic solvent nanofiltration (OSN): Part A. Effect of polymer/solvent/non-solvent system choice." Journal of Membrane Science 381(1-2): 152-162.

Soroko, I., M. Makowski, F. Spill and A. Livingston (2011). "The effect of membrane formation parameters on performance of polyimide membranes for organic solvent nanofiltration (OSN). Part B: Analysis of evaporation step and the role of a co-solvent." Journal of Membrane Science 381(1-2): 163-171.

Soroko, I., M. Sairam and A. G. Livingston (2011). "The effect of membrane formation parameters on performance of polyimide membranes for organic solvent nanofiltration (OSN). Part C. Effect of polyimide characteristics." Journal of Membrane Science 381(1-2): 172-182.

Sorribas, S., P. Gorgojo, C. Téllez, J. Coronas and A. G. Livingston (2013). "High Flux Thin Film Nanocomposite Membranes Based on Metal-Organic Frameworks for Organic Solvent Nanofiltration." Journal of the American Chemical Society 135(40): 15201-15208.

Stafie, N., D. F. Stamatialis and M. Wessling (2005). "Effect of PDMS cross-linking degree on the permeation performance of PAN/PDMS composite nanofiltration membranes." Separation and Purification Technology 45(3): 220-231.

Stamatialis, D. F., N. Stafie, K. Buadu, M. Hempenius and M. Wessling (2006). "Observations on the permeation performance of solvent resistant nanofiltration membranes." Journal of Membrane Science 279(1-2): 424-433.

Struzyńska-Piron, I., M. R. Bilad, J. Loccufier, L. Vanmaele and I. F. J. Vankelecom (2014). "Influence of UV curing on morphology and performance of polysulfone membranes containing acrylates." Journal of Membrane Science 462: 17-27.

Struzynska-Piron, I., J. Loccufier, L. Vanmaele and I. F. J. Vankelecom (2013). "Synthesis of solvent stable polymeric membranes via UV depth-curing." Chemical Communications 49(98): 11494-11496. 
Sun, S.-P., T.-S. Chung, K.-J. Lu and S.-Y. Chan (2014). "Enhancement of flux and solvent stability of Matrimid® thin-film composite membranes for organic solvent nanofiltration." AIChE Journal 60(10): 3623-3633.

Tanh Jeazet, H. B., C. Staudt and C. Janiak (2012). "Metal-organic frameworks in mixedmatrix membranes for gas separation." Dalton Transactions 41(46): 14003-14027.

Tarleton, E. S., J. P. Robinson, C. R. Millington and A. Nijmeijer (2005). "Non-aqueous nanofiltration: solute rejection in low-polarity binary systems." J. Membr. Sci. 252(1-2): 123-131.

Tarleton, E. S., J. P. Robinson, C. R. Millington, A. Nijmeijer and M. L. Taylor (2006). "The influence of polarity on flux and rejection behaviour in solvent resistant nanofiltrationExperimental observations." Journal of Membrane Science 278(1-2): 318-327.

Tin, P. S., T. S. Chung, Y. Liu, R. Wang, S. L. Liu and K. P. Pramoda (2003). "Effects of cross-linking modification on gas separation performance of Matrimid membranes." Journal of Membrane Science 225(1-2): 77-90.

Tsuru, T., M. Miyawaki, H. Kondo, T. Yoshioka and M. Asaeda (2003). "Inorganic porous membranes for nanofiltration of nonaqueous solutions." Sep. Purif. Technol. 32(1-3): 105109.

Tsuru, T., M. Narita, R. Shinagawa and T. Yoshioka (2008). "Nanoporous titania membranes for permeation and filtration of organic solutions." Desalination 233(1-3): 1-9.

Valtcheva, I. B., S. C. Kumbharkar, J. F. Kim, Y. Bhole and A. G. Livingston (2014). "Beyond polyimide: Crosslinked polybenzimidazole membranes for organic solvent nanofiltration (OSN) in harsh environments." Journal of Membrane Science 457(0): 62-72.

Valtcheva, I. B., P. Marchetti and A. G. Livingston (2015). "Crosslinked polybenzimidazole membranes for organic solvent nanofiltration (OSN): Analysis of crosslinking reaction mechanism and effects of reaction parameters." Journal of Membrane Science 493: 568-579. 
Van der Bruggen, B., J. Geens and C. Vandecasteele (2002). "Influence of organic solvents on the performance of polymeric nanofiltration membranes." Separation Science and Technology 37(4): 783-797.

Van Doorslaer, C., D. Glas, A. Peeters, A. Cano Odena, I. Vankelecom, K. Binnemans, P. Mertens and D. De Vos (2010). "Product recovery from ionic liquids by solvent-resistant nanofiltration: application to ozonation of acetals and methyl oleate." Green Chemistry 12(10): 1726-1733.

Vandezande, P., L. E. M. Gevers and I. F. J. Vankelecom (2008). "Solvent resistant nanofiltration: separating on a molecular level." Chemical Society Reviews 37(2): 365-405.

Vandezande, P., X. Li, L. E. M. Gevers and I. F. J. Vankelecom (2009). "High throughput study of phase inversion parameters for polyimide-based SRNF membranes." Journal of Membrane Science 330(1-2): 307-318.

Vanherck, K., A. Aerts, J. Martens and I. Vankelecom (2010). "Hollow filler based mixed matrix membranes." Chem. Commun. 46(14): 2492-2494.

Vanherck, K., A. Cano-Odena, G. Koeckelberghs, T. Dedroog and I. Vankelecom (2010). "A simplified diamine crosslinking method for PI nanofiltration membranes." Journal of Membrane Science 353(1-2): 135-143.

Vanherck, K., G. Koeckelberghs and I. F. J. Vankelecom (2013). "Crosslinking polyimides for membrane applications: A review." Progress in Polymer Science 38(6): 874-896.

Vanherck, K., P. Vandezande, S. O. Aldea and I. F. J. Vankelecom (2008). "Cross-linked polyimide membranes for solvent resistant nanofiltration in aprotic solvents." Journal of Membrane Science 320(1-2): 468-476.

Vankelecom, I. F. J., K. De Smet, L. E. M. Gevers, A. Livingston, D. Nair, S. Aerts, S. Kuypers and P. A. Jacobs (2004). "Physico-chemical interpretation of the SRNF transport mechanism for solvents through dense silicone membranes." Journal of Membrane Science 231(1-2): 99-108. 
Vanneste, J., D. Ormerod, G. Theys, D. Van Gool, B. Van Camp, S. Darvishmanesh and B. Van der Bruggen (2013). "Towards high resolution membrane-based pharmaceutical separations." Journal of Chemical Technology \& Biotechnology 88(1): 98-108.

Volkov, A. V., V. V. Parashchuk, D. F. Stamatialis, V. S. Khotimsky, V. V. Volkov and M. Wessling (2009). "High permeable PTMSP/PAN composite membranes for solvent nanofiltration." J. Membr. Sci. 333(1-2): 88-93.

Xie, Z., B. Dao, J. Hodgkin, M. Hoang, A. Hill and S. Gray (2011). "Synthesis and characterization of hybrid organic-inorganic materials based on sulphonated polyamideimide and silica." Journal of Polymer Research 18(5): 965-973.

Xing, D. Y., S. Y. Chan and T.-S. Chung (2014). "The ionic liquid [EMIM]OAc as a solvent to fabricate stable polybenzimidazole membranes for organic solvent nanofiltration." Green Chemistry 16(3): 1383-1392.

Zhang, H. Q., Y. J. Zhang, L. B. Li, S. Zhao, H. O. Ni, S. K. Cao and J. T. Wang (2014). "Cross-linked polyacrylonitrile/polyethyleneimine-polydimethylsiloxane composite membrane for solvent resistant nanofiltration." Chem. Eng. Sci. 106(0): 157-166.

Zhang, Y., R. Wang, S. Yi, L. Setiawan, X. Hu and A. G. Fane (2011). "Novel chemical surface modification to enhance hydrophobicity of polyamide-imide (PAI) hollow fiber membranes." Journal of Membrane Science 380(1-2): 241-250.

Zhao, Q., Q. F. An, Y. Ji, J. Qian and C. Gao (2011). "Polyelectrolyte complex membranes for pervaporation, nanofiltration and fuel cell applications." Journal of Membrane Science 379(1-2): 19-45.

Zornoza, B., C. Tellez, J. Coronas, J. Gascon and F. Kapteijn (2013). "Metal organic framework based mixed matrix membranes: An increasingly important field of research with a large application potential." Microporous and Mesoporous Materials 166(0): 67-78. 